\title{
Autofluorescence of atmospheric bioaerosols - fluorescent biomolecules and potential interferences
}

\author{
C. Pöhlker ${ }^{1}$, J. A. Huffman ${ }^{1,2}$, and U. Pöschl ${ }^{1}$ \\ ${ }^{1}$ Max Planck Institute for Chemistry, Biogeochemistry Department, P.O. Box 3060, 55020 Mainz, Germany \\ ${ }^{2}$ University of Denver, Department of Chemistry and Biochemistry, 2190 E. Illif, Denver, Colorado, 80208, USA \\ Correspondence to: J. A. Huffman (alex.huffman@du.edu)
}

Received: 12 July 2011 - Published in Atmos. Meas. Tech. Discuss.: 16 September 2011

Revised: 16 December 2011 - Accepted: 19 December 2011 - Published: 9 January 2012

\begin{abstract}
Primary biological aerosol particles (PBAP) are an important subset of air particulate matter with a substantial contribution to the organic aerosol fraction and potentially strong effects on public health and climate. Recent progress has been made in PBAP quantification by utilizing real-time bioaerosol detectors based on the principle that specific organic molecules of biological origin such as proteins, coenzymes, cell wall compounds and pigments exhibit intrinsic fluorescence. The properties of many fluorophores have been well documented, but it is unclear which are most relevant for detection of atmospheric PBAP. The present study provides a systematic synthesis of literature data on potentially relevant biological fluorophores. We analyze and discuss their relative importance for the detection of fluorescent biological aerosol particles (FBAP) by online instrumentation for atmospheric measurements such as the ultraviolet aerodynamic particle sizer (UV-APS) or the wide issue bioaerosol sensor (WIBS).
\end{abstract}

In addition, we provide new laboratory measurement data for selected compounds using bench-top fluorescence spectroscopy. Relevant biological materials were chosen for comparison with existing literature data and to fill in gaps of understanding. The excitation-emission matrices (EEM) exhibit pronounced peaks at excitation wavelengths of $\sim 280 \mathrm{~nm}$ and $\sim 360 \mathrm{~nm}$, confirming the suitability of light sources used for online detection of FBAP. They also show, however, that valuable information is missed by instruments that do not record full emission spectra at multiple wavelengths of excitation, and co-occurrence of multiple fluorophores within a detected sample will likely confound detailed molecular analysis. Selected non-biological materials were also analyzed to assess their possible influence on FBAP detection and generally exhibit only low levels of background-corrected fluorescent emission. This study strengthens the hypothesis that ambient supermicron particle fluorescence in wavelength ranges used for most FBAP instruments is likely to be dominated by biological material and that such instrumentation is able to discriminate between FBAP and non-biological material in many situations. More detailed follow-up studies on single particle fluorescence are still required to reduce these uncertainties further, however.

\section{Introduction}

\subsection{Primary biological aerosol particles}

Primary biological aerosol particles (PBAP), also referred to as bioaerosols, are a diverse collection of small pieces of material emitted directly from the biosphere into the atmosphere (Després et al., 2012). They are globally ubiquitous, in some cases can dominate suspended particle concentrations, and comprise a diverse selection of particle types, including: whole organisms (e.g. bacteria, algae), reproductive entities (e.g. pollen, spores from fungi, bacteria, ferns, mosses), biopolymers (e.g. DNA, chitin, cellulose and other polysaccharides), plant debris, insect parts, and decaying biomass (e.g. Gregory, 1973; Madelin, 1994; Cox and Wathes, 1995; Andreae and Crutzen, 1997; Jones and Harrison, 2004; Jaenicke, 2005; Pöschl, 2005; Elbert et al., 2007; Jaenicke et al., 2007; Bauer et al., 2008; Pöschl et al., 2010; Després et al., 2012). PBAP can span several orders 
of magnitude in particle diameter, from a few nanometers (e.g. viruses) to hundreds of micrometers (e.g. plant debris), making analysis challenging. A number of studies have indicated that PBAP may comprise large fractions of ambient particulate matter (PM) in many environments. Microscopic investigations have shown that PBAP can account for up to $\sim 30 \%$ of fine $(<1 \mu \mathrm{m})$ and up to $\sim 70 \%$ of coarse $(>1 \mu \mathrm{m})$ $\mathrm{PM}$ in rural and rain forest air, and estimates of PBAP emissions range from $\sim 60 \mathrm{Tg} \mathrm{a}^{-1}$ of fine PM to $\sim 1000 \mathrm{Tg} \mathrm{a}^{-1}$ in all size ranges (Penner, 1994; Jaenicke, 2005; Elbert et al., 2007). Fungal spores in particular account for a large proportion of PBAP with typical mass concentrations of $\sim 1 \mu \mathrm{g} \mathrm{m}{ }^{-3}$ in continental boundary layer air and estimated global emissions in the order of $\sim 50 \mathrm{Tg} \mathrm{a}^{-1}$ (Elbert et al., 2007).

The aerial dispersal and transport of biological aerosols, particularly reproductive material such as spores and pollen, is an important pathway for the spread of organisms within and across ecosystems (Gregory, 1973; Elbert et al., 2007). Bioaerosols may act as giant cloud condensation nuclei (CCN) and ice nuclei (IN) (e.g. Dingle, 1966; Schnell and Vali, 1972; Lohmann and Feichter, 2005; Sun and Ariya, 2006; Möhler et al., 2007; Christner et al., 2008), thus influencing global climate by affecting cloud formation and precipitation. They also play a crucial role in public health by spreading disease to humans (e.g. tuberculosis, influenza), animals (e.g. anthrax, brucellosis) and crops (e.g. rust, smut) and by causing allergies (e.g. Lacey and Dutkiewicz, 1994; Linskens and Cresti, 2000; Brown and Hovmoller, 2002; Douwes et al., 2003; Franze et al., 2005). As a result, quantification of local PBAP concentrations and identification of individual species or classes is essential for diverse scientific fields such as climatology, atmospheric science, human health, crop science and agriculture, biogeography, and others. Within the last two decades, especially, the detection of bioaerosols used as biological warfare agents (BWA) has also become important, both on the battlefield and with respect to domestic terrorism (e.g. Hill et al., 1995; Pinnick et al., 1995; Primmerman, 2000; Ho, 2002; Lim et al., 2005; Manninen et al., 2008).

Existing methods for PBAP measurement have historically been off-line techniques which suffer from poor time resolution (hours to days), requiring costly and time consuming sample analysis (Griffiths and Decosemo, 1994). As a result, much work has been done to report qualitative and semi-quantitative observations of certain ambient bioaerosol classes, but systematic efforts to quantify PBAP as a whole have been limited (e.g. Lighthart and Shaffer, 1995; Matthias-Maser et al., 2000). Counting methods based on cultivation of viable airborne organisms cause certain methodologically difficulties that make comparison with other techniques difficult. For example, the "great plate count anomaly" describes the well known problem that only a small fraction (typically $<10 \%$, often $<1 \%$ ) of airborne microorganisms form colonies on a typical culture media (Amann et al., 1995; Heidelberg et al., 1997; Chi and $\mathrm{Li}, 2007$ ), thus leading to a significant underestimation of the actual viable airborne bioaerosol concentration. The vast remaining number of airborne microorganisms can be described as viable but non-culturable (VBNC), indicating very low metabolic activity or resting dormant state (Roszak and Colwell, 1987). Even non-viable PBAP can be important for atmospheric, biological, and human health concerns, however.

Cultivation methods only attempt to count full, viable (living) organisms, while other physical or chemical techniques are able to selectively analyze non-viable cells or fragments of biological material. In recent years virtually every available chemical, biological, and physical technique of analysis has been applied to the measurement of ambient PBAP, and a full review of these attempts is well beyond the scope of this manuscript (e.g. Spurny, 1994; Ho, 2002; Georgakopoulos et al., 2009; Després et al., 2012; Xu et al., 2011). Mass spectrometry (MS), in its various forms, has been successful at detecting PBAP with high time resolution and detailed chemical identification of analyzed particles (e.g. Parker et al., 2000; Fergenson et al., 2004; van Wuijckhuijse et al., 2005). Among modern microbiological methods, polymerase chain reaction (PCR) and quantitative PCR (qPCR) are promising tools for identification and quantification of cells from a specific organism via identification of sampled DNA, although the techniques are not capable of providing an estimate of the total PBAP concentration (e.g. Després et al., 2007; Bowers et al., 2009; Fröhlich-Nowoisky et al., 2009; Bowers et al., 2011). Epifluorescence microscopy, particularly in combination with the use of fluorescent dyes, has been a frequently utilized technique for PBAP quantification and refers to the microscopic imaging of the distribution of fluorescent compounds in cells or tissue (e.g. Hobbie et al., 1977; Kepner and Pratt, 1994). By staining specific cell constituents (e.g. DNA, proteins, cell walls) PBAP can be analyzed regardless of the metabolic state of the organism, thus overcoming the problem of poor culturability. The commercial availability of a wide selection of fluorescent dyes allows a flexible and selective quantification of many classes of microorganisms (McFeters et al., 1995; Li et al., 2004). The method suffers from the need for time-consuming and, therefore, costly sample analysis, however. Instruments able to discriminate biological content in real-time based on the emission of laserinduced fluorescence (LIF) have recently become commercially available and are among the most promising techniques for ambient atmospheric PBAP analysis (e.g. Pinnick et al., 1995; Hairston et al., 1997; Kaye et al., 2000). While these do not offer the molecular specificity or detailed imaging capabilities of microscopy, many instruments are able to provide an estimate of PBAP properties in real-time, with high time and size resolution (e.g. Huffman et al., 2010). 


\subsection{Physical principles of fluorescence}

Spectroscopy refers to a wide class of analytical techniques where an analyte is selectively interrogated through interaction with a region of the electromagnetic radiation, and has been widely applied to virtually every scientific field, including the measurement of biological aerosols. For the purpose of clarifying arguments later in the paper we present a brief overview of key spectroscopic principles here. Analyte molecules exposed to incident radiation can either absorb or scatter incoming photons. If photons are absorbed or inelastically scattered, energy is imparted to a molecule that can be dissipated either radiatively, non-radiatively, or through a combination of both (e.g. fluorescence, phosphorescence). Molecular fluorescence can be seen mechanistically as an inelastic light scattering process (i.e. energy is imparted to the molecule) with three distinct electronic steps: (I) Photon absorption causes an electron to transition from the lowest vibrational state of the electronic ground state of the molecule to a higher vibrational state of an excited electronic state. (II) This is followed by dissipation of energy through non-radiative decay (heat) and transition of the electron to the lowest vibrational level of the excited electronic state. (III) The electron can then return to the electronic ground state by radiative emission (fluorescence) or through a variety of non-radiative processes (quenching), depending largely on the local molecular environment. Many different quenching mechanisms are possible, such as collision quenching (i.e. by oxygen or water) and concentration quenching (i.e. self-quenching and inner-filtering effects) (Sinski and Exner, 2007). Phosphorescence is mechanistically similar to fluorescence, except that a spin change occurs due to an intersystem conversion in the excited electronic state. This leads to the practical distinction that the timescale of radiative emission for fluorescence (ns) is up to several orders of magnitude shorter than for phosphorescence ( $\mu$ s-ms) (RichardsKortum and SevickMuraca, 1996).

Both excitation $\left(\lambda_{\mathrm{ex}}\right)$ and emission wavelengths $\left(\lambda_{\mathrm{em}}\right)$ are characteristic for a given fluorophore, and the most likely electron transition pathways for that molecule are determined by the overlap integral of the corresponding vibrational wave functions. Usually spontaneous fluorescent emission is specific for a certain fluorophore and its molecular environment and occurs at relatively narrow, defined $\lambda_{\mathrm{em}}$. Molecular excitation, however, can occur over a comparatively wide spectral range due to several accessible electron transition pathways, but is still an important piece of information for fluorophore assignment. The spectral difference between $\lambda_{\text {ex }}$ and $\lambda_{\mathrm{em}}$ is referred to as the Stokes shift $\left(\Delta \lambda_{\text {Stokes }}\right)$. An important feature of fluorescence is the independence of $\lambda_{\mathrm{em}}$ with respect to $\lambda_{\text {ex }}$ which means that the qualitative appearance of the emission peak is similar for different excitation wavelengths. This is due to the fact that all nonradiative decay processes end in the lowest vibrational level of the first excited electronic state from where fluorescent relaxation occurs. For further details see Lakowicz (1999), Kunnil (2005) and Ramanujam (2006).

The fluorescence properties of a molecule can be characterized by parameters of steady state fluorescence spectroscopy, such as $\lambda_{\text {ex }}$ and $\lambda_{\text {em }}$ or the quantum yield $\Phi$ (fluorescent emission events per photons absorbed). Time resolved measurements also analyze the lifetime $\tau$ of the excited state (average time the electron spends in the excited electronic state until it returns to the ground state). Large polymers, heterocyclic aromatic compounds, or molecules with conjugated double bonds are among classes of molecules known to be especially efficient at emitting fluorescence, particularly when nitrogenous substitutions are present. The incident light in the ultraviolet (UV) to visible range predominantly promotes electronic $\pi-\pi^{*}$ transitions. Accordingly the size of the conjugated $\pi$-bond system and the identity of adjacent electron donating or withdrawing groups determine the spectral properties of the fluorescence process.

Fluorescence spectroscopy and imaging have become tools of enormous analytical importance, especially within biological research. The techniques can be divided into the general classes of extrinsic and intrinsic fluorescence. Extrinsic fluorescence refers to the addition of exogenous fluorophores to a set of analyte molecules in order to highlight biological components not easily distinguishable otherwise. This is achieved by insertion of a synthetic fluorescent probe into an organism or material in order to perform selective labeling of a certain target. As a result of its wide use, a large variety of fluorescent probes have become commercially available for selective labeling of macromolecules, cell parts or tissue and for subsequent analysis by various imaging techniques. For example fluorescent dyes such as 4',6-diamidino-2-phenylindole (DAPI) are useful tools to visualize DNA and RNA. Fluorescence in-situ hybridization (FISH) allows the labeling of complete DNA sequences in order to selectively detect and quantify specific organisms. In molecular biology the gene of the green fluorescent protein (GFP) has been introduced in many organisms where GFP is expressed for selective in vivo labeling of certain cell parts. These methods are powerful, in part, because they enable the combination of highly selective labeling of a target molecule with tools for quick, quantitative and non-invasive detection of fluorescence signals within tissue and biological material. Intrinsic fluorescence, or autofluorescence, in contrast, is caused by fluorescent molecules (fluorophores) which exist as a natural component of the analyte material. A large number of biological molecules and compounds are known to exhibit fluorescence light emission. Certain amino acids and coenzymes are among the most commonly analyzed biofluorophores, but numerous other metabolites and biogenic molecules emit fluorescence. Biological samples most often contain a multi-component mixture of biofluorophores, and, accordingly, the overall fluorescent emission often comprises a superposition of individual signals. 
Intrinsic fluorescence has been extensively utilized in various fields such as tissue diagnostic (e.g. Koenig and Schneckenburger, 1994; Andersson Engels et al., 1997), bioprocess monitoring (e.g. Marose et al., 1998; Pons et al., 2004), plant physiology (e.g. Roshchina, 2003, 2004), and environmental studies (e.g. Hudson et al., 2007; Wedborg et al., 2007).

\subsection{History of online detection of fluorescent aerosols}

While the use of fluorescence techniques to image biological specimens under a microscope is well established, the application of fluorescence to biological aerosol measurement has received significant attention only within the last decades and increasingly so recently. In particular, much effort has been placed on the use of laser/light-induced fluorescence (LIF) for online particle detection, because it allows the non-invasive, in-situ detection of particles with high temporal resolution. Most of the progress in this field has been a result of scientific communities focused on the detection of biological warfare agents (BWA) (e.g. Hill et al., 1995; Cheng et al., 1999; Seaver et al., 1999; Kaye et al., 2000; Ho, 2002). BWA sensors are designed to detect suspicious agents reliably, even in low concentrations, with a low falsepositive rate and with short response. Especially challenging is the rapid and selective recognition of specific organisms on top of a diverse and variable ambient aerosol background. Naturally occurring PBAP such as pollen and fungal spores as well as certain non-biogenic aerosols (e.g. soot, industrial plumes) could, in some cases, mimic the BWA signal and trigger a false-alarm. Reliable distinction of analyzed particles is not possible by single-wavelength LIF, and so many instrument developers have added the ability to monitor additional optical properties of the sampled particles, such as: LIF at a second wavelength (dual-wavelength LIF), optical size, shape factor or light absorption.

Most BWA agents are bacteria and bacterial spores (bacillus anthracis, yersinia pestis), viruses (ebola virus, Marburg virus) and toxins (rizin, botulinum toxin) (Hawley and Eitzen, 2001; Kamboj et al., 2006). It has been shown that amino acids (i.e. tryptophan) and some coenzymes (i.e. $\mathrm{NAD}(\mathrm{P}) \mathrm{H}$, flavins, vitamin $\mathrm{B}_{6}$ and $\mathrm{B}_{9}$ compounds) dominate the fluorescence properties of these agents, particularly bacteria (Dalterio et al., 1987; Kopczynski et al., 2005; Johansson and Liden, 2006; Wlodarski et al., 2006), thus simplifying the list of molecules desired for online detection. Viable bacteria usually exhibit a coenzyme signal due to increased metabolic activity and an amino acid signal due to proteins and peptides. In contrast, viruses and peptide toxins exclusively show a protein signal. Accordingly, BWA sensors are individually optimized to match the spectral properties of these agents.

Decades of research by military agencies interested in detecting BWA have recently led to the development and commercialization of several instruments now available for civilian use and that have begun to contribute to atmospheric measurement and research. The ultraviolet aerodynamic particle sizer (UV-APS), for example, provides aerodynamic particle sizing and fluorescence information via singlewavelength LIF by a pulsed Nd:YAG laser $\left(\lambda_{\mathrm{ex}}=355 \mathrm{~nm}\right.$; $\lambda_{\text {em }}=420-575 \mathrm{~nm}$ ) (Hairston et al., 1997; Brosseau et al., 2000) and is sold by TSI, Inc. (Shoreview, MN, USA). The University of Hertfordshire wide issue bioaerosol sensor (WIBS) optically provides particle sizing, an estimate of particle sphericity, and fluorescence information based on dual-wavelength LIF by a Xe-flashlamp $\left(\lambda_{\text {ex }, 1}=280 \mathrm{~nm}\right.$, $\lambda_{\text {ex }, 2}=370 \mathrm{~nm} ; \lambda_{\text {em }}=310-400$ and $400-600 \mathrm{~nm}$ ) (Kaye et al., 2000; Stanley et al., 2011). The Bristol Industrial and Research Associates Limited (BIRAL) aerosol fluorescence sensor (AFS) provides particle size and sphericity based on light scattering and fluorescence information after excitation from a UV flash lamp $\left(\lambda_{\mathrm{ex}}=280 \mathrm{~nm} ; \lambda_{\mathrm{em}}=330-650\right.$ and 420-600 nm). Both, UV-APS and WIBS have been utilized for ambient measurements in urban European (Huffman et al., 2010; Gabey, 2011) and in pristine rainforest (Gabey et al., 2010; Pöschl et al., 2010; Huffman et al., 2011) environments. These instruments have provided the first continuous and quantitative measurements of fluorescent biological aerosol particles (FBAP) with both high temporal and size resolution, thus providing a lower limit of PBAP concentrations (Huffman et al., 2010). Similar future experiments will help provide crucial input estimates of PBAP flux for global transport models (e.g. Burrows et al., 2009; Heald and Spracklen, 2009; Hoose et al., 2010).

\subsection{Fluorescence spectral maps and online FBAP detectors}

Wavelength-dependent fluorescence emission spectra, recorded as a function of excitation wavelength, can be plotted as a three-dimensional landscape and thus referred to as an excitation-emission matrix (EEM). Such plots, accordingly, relay a broad collection of information about the steady-state autofluorescence properties of a compound and can be regarded as a unique, sample-specific fingerprint. Similar spectral summaries have been applied as valuable tools in various scientific fields, such as environmental (Kunnil, 2005; Hudson et al., 2007; Wedborg et al., 2007) and medical science (DaCosta et al., 2003; Chang et al., 2005), because they allow a quick, quantitative and non-invasive in-situ characterization with high sensitivity (detection limit: $10^{-8}-10^{-9} \mathrm{M}$ ) (Miao et al., 2003). EEMs may also help facilitate the qualitative assignment of spectral modes to known fluorophores, thus providing insights into the molecular origin of fluorescence. This kind of analysis in the laboratory, in complement to ambient PBAP detection, is particularly necessary for the identification of fluorophores responsible for fluorescence within atmospheric biological particles, and consequently may also allow the estimation of the fluorophore selectivity of a given real-time instrument. 
Light scattering effects can complicate peak assignment of fluorescence spectra and, in particular, quantification of fluorescence. Three types of light scattering are typically important for laboratory fluorescence measurements. Rayleigh scattering can originate from both sample and solvent (i.e. water) molecules, which are smaller than the incident wavelength, and Tyndall scattering is a strongly wavelength-dependent reflection process from particulate matter in a suspension (Zepp et al., 2004). Both are types of elastic scattering, meaning that the incident wavelength is identical to the emitted or reflected wavelength $\left(\lambda_{\mathrm{em}}=\lambda_{\mathrm{ex}}\right)$. Inelastic Raman scattering from solvent molecules (i.e. water $\mathrm{O}-\mathrm{H}$ stretching mode) is a much weaker process and appears at slightly longer wavelengths than the elastic scattering signal in solution-phase samples (Ewald et al., 1983; Zepp et al., 2004; Bhartia et al., 2008). If present, each scattering effect can appear as peak in a given emission spectrum and can be further distorted by non-idealities in the spectrometer wavelength dispersion or filtering. For example, elastic scattering of $350 \mathrm{~nm}$ incident light will exhibit a sharp peak at the same wavelength in the emission spectrum, referred to as a first order effect $\left(\lambda_{\text {em }}=\lambda_{\text {ex }}\right)$, but diffraction gratings can also introduce peaks at emission wavelengths of diffraction orders. Thus second order diffraction would allow the same $350 \mathrm{~nm}$ incident photons to appear at $700 \mathrm{~nm}\left(\lambda_{\mathrm{em}}=2 \lambda_{\mathrm{ex}}\right)$ in the emission spectra. Higher order (e.g. 2nd, 3rd) diffraction, as well as 0-th order diffraction are also possible, but less intense. Imperfect wavelength filtering also allows photons with shorter or longer wavelength than desired to pass through the instrument optics and this is referred to as a form of "light leakage". This phenomenon broadens the incoming wavelength peak and is noticeable by size of the tail of elastic scattering signal. For samples in solution the emission spectrum of pure solvent can be subtracted to reduce the influence of these interferences. No similar subtraction is possible for suspended or solid-phase samples, however, and scattering effects can, therefore, introduce artificial features to spectra.

Because fluorescence is an inelastic light scattering process, emitted radiation is by definition red-shifted with respect to the incident radiation $\left(\lambda_{\mathrm{em}}>\lambda_{\mathrm{ex}}\right)$. The Stokes shift is, therefore, also by definition positive. Typical $\Delta \lambda_{\text {Stokes }}$ values of naturally occurring fluorophores are usually approximately $10-200 \mathrm{~nm}$, which means that fluorescence signals usually appear between the 1st and 2nd order diffraction peaks of elastically scattered light (Lakowicz, 1999). As an example, contour plots of three frequently investigated biological fluorophores (tryptophan, NADPH and riboflavin) are shown in Fig. 1. Fluorescence modes usually occur as broad and relatively featureless peaks. As discussed in Sect, 1.2, electron transition can occur to different vibrational energy levels. The resulting vibrational fine structure can be seen for samples in the gas phase where fewer molecular collisions occur, but are usually not resolvable for condensed phase samples. Instead, the appearance of multiple distinct excitation modes (i.e. for riboflavin) is due to different electron

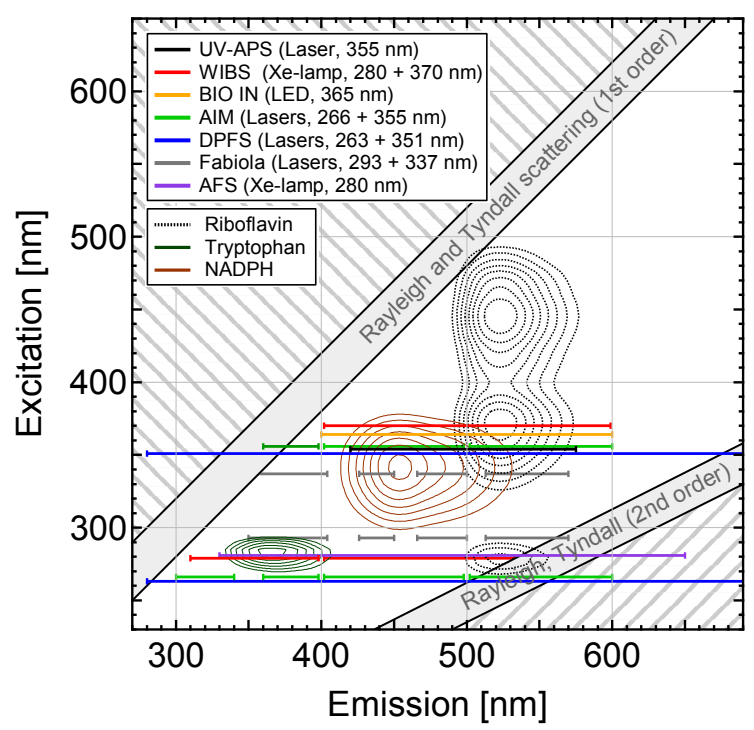

Fig. 1. Conceptual EEM displaying: (a) fluorescence data area (white), areas strongly influenced by Rayleigh and Tyndall light scattering (grey diagonal bars), areas without meaningful data (grey stripes); (b) contour lines for the fluorophores tryptophan, NADPH and riboflavin; (c) operational range of selected bioaerosol detectors represented by horizontal colored lines. Length of individual lines indicates measured emission band for a certain excitation wavelength shown as sharp line for purpose of clarity. Singlewavelength detectors are represented by one line, dual-wavelength detectors by two lines. Instruments shown with spectral specification: UV-APS (laser, $\lambda_{\mathrm{ex}}=355 \mathrm{~nm}, \lambda_{\mathrm{em}}=420-575 \mathrm{~nm}$ ) (Hairston et al., 1997); WIBS (Xe-lamps, $\lambda_{\mathrm{ex}, 1}=280, \lambda_{\mathrm{em}, 280}=310-400$,

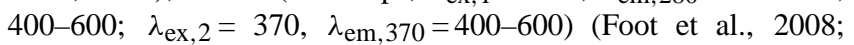
Gabey, 2011); DPFS (lasers, $\lambda_{\mathrm{ex}, 1}=263, \lambda_{\mathrm{em}, 263}=280-700$; $\lambda_{\mathrm{ex}, 2}=351, \lambda_{\mathrm{em}, 351}=280-700$ ) (Pan et al., 2011); AIM (lasers, $\lambda_{\mathrm{ex}, 1}=266, \quad \lambda_{\mathrm{em}, 266}=300-340, \quad 360-400, \quad 400-500, \quad 500-600$; $\left.\lambda_{\mathrm{ex}, 2}=355, \lambda_{\mathrm{em}, 355}=360-400,400-500,500-600\right)$ (Sivaprakasam et al., 2004, 2009); Fabiola (lasers, $\lambda_{\mathrm{ex}, 1}=293, \lambda_{\mathrm{em}, 293}=350$ $404,426-450,466-500,513-570 ; \lambda_{\text {ex }, 2}=337, \lambda_{\text {em }, 337}=350-404$, 426-450, 466-500, 513-570) (Feugnet et al., 2008); SPFA (laser, $\left.\lambda_{\mathrm{ex}}=266, \lambda_{\mathrm{em}, 266}=300-400,400-600\right)$ (Snyder et al., 2004); BIO IN ( $\left.\lambda_{\mathrm{ex}}=365, \lambda_{\mathrm{em}, 365}=400-600\right)$ (Bundke et al., 2010); AFS $\left(\lambda_{\mathrm{ex}}=280, \lambda_{\mathrm{em}, 280}=330-650,420-650\right)$.

transition pathways (Lakowicz, 1999). Figure 1 also conceptually shows how EEMs can be utilized in this context. According to Thygesen et al. (2004) three different areas can be distinguished in an EEM: (I) the fluorescence data area (white), (II) areas dominated by strong light scattering interferences (gray diagonal bars), and (III) an area that lacks physical meaning because $\lambda_{\mathrm{em}}<\lambda_{\mathrm{ex}}$ (gray stripes in upper left corner). Additionally, we have removed data from the lower right corner of each EEM for data shown here. In this region spurious peaks may appear which are caused by second order diffraction of the fluorescent light at the emission grating. As mentioned, the Raman signal of solvents can also be observed in certain situations and would appear in Fig. 1 
as a weak diagonal signal whose slope is 0.75 times that of the 1st order elastic scattering line. Raman scattering was not directly observed in any measurements reported here, however, and will not be discussed further.

Figure 1 also summarizes the spectral ranges over which several current bioaerosol instruments detect FBAP. Though somewhat independent in terms of instrument design, only two relatively narrow ranges of excitation $(\sim 280 \mathrm{~nm}$ and $\sim 360 \mathrm{~nm}$ ) have been utilized for most FBAP detectors. Excitation at $\sim 280 \mathrm{~nm}$ has typically been chosen to highlight the presence of tryptophan as a marker for proteins, and has therefore been used to estimate the total biological fraction in environmental samples. Excitation at $\sim 360 \mathrm{~nm}$ has typically been chosen to highlight $\mathrm{NAD}(\mathrm{P}) \mathrm{H}$ as a measure for the viable biological fraction, because they are directly linked to the cellular energy metabolism. These assumptions could potentially be problematically simplistic, as will be discussed further. Several dual-wavelength biodetectors have been designed to provide fluorescence from multiple wavelengths of excitation in an attempt to quantify both the whole FBAP fraction and an estimate of its viable subset (i.e. Kaye et al., 2005; Pan et al., 2010).

Selectivity, or the ability to separate fluorophore types within analyzed particles, is a key issue in the design of bioaerosol detectors. A reliable estimate of PBAP concentration requires clear distinction between biological and nonbiological particles. It has been suggested that FBAP can be seen as a lower limit estimate for PBAP, because not all biofluorophores will fluoresce at a given wavelength, leading to an underestimation of PBAP concentration (Huffman et al., 2010). However, the exact relationship of FBAP and PBAP is complicated and still unknown. In addition, the ability to discriminate between viable and non-viable organisms based on LIF of key metabolic coenzymes (e.g. NADH) has been a key assumption in the development of many FBAP detectors. This separation and distinction has been successfully shown under certain defined conditions (e.g. in bioreactors and for aerosolized laboratory bacteria) but is highly uncertain under complex atmospheric conditions (Marose et al., 1998; Agranovski et al., 2003; Johansson and Liden, 2006; Li et al., 2011). Based on the amount of biological fluorophores that also fluoresce at wavelengths typically used to determine cell viability (see Table 1 and following discussion) it is almost certain that the signal at $\sim 360 \mathrm{~nm}$, typically assumed to indicate the presence of $\mathrm{NAD}(\mathrm{P}) \mathrm{H}$, reflects more than just viable FBAP. In all cases, however, detailed EEM plots can be a helpful tool to visualize the combination of fluorophores emission signals and the instruments operational range.

\subsection{Motivation of fluorophore literature synthesis}

As discussed, much work has been performed by the BWA community and more recently by researchers interested in ambient PBAP analysis to utilize autofluorescence for the search of bioaerosols in the atmosphere, taking advantage of the fact that biological material contains characteristic intrinsic fluorophores. Both biological and non-biological material can exhibit intrinsic fluorescence, however, and so the challenge of discriminating between the two requires a firm knowledge of the corresponding fluorophores. Amino acids with aromatic residues (tryptophan, tyrosine, phenylalanine) and several coenzymes (e.g. NAD $(\mathrm{P}) \mathrm{H}$, flavins, and vitamin $\mathrm{B}_{9}$ compounds) have been generally used by these communities as the most important fluorophores in biological cells and particles (i.e. Davitt et al., 2005; Kaye et al., 2005; Wlodarski et al., 2006; Pan et al., 2010). Whereas amino acids occur in all organisms as building blocks of proteins, coenzymes such as NADH and flavins have only been shown to occur in actively metabolizing organisms and therefore may be specific markers for living cells. Living bacteria actively metabolize and are an important subset of ambient PBAP, but other essential constituents, such as fungal and bacterial spores as well as pollen, do not exhibit measureable metabolic activity (Setlow and Setlow, 1977). As such, they may not contain significant concentrations of NADH, though this is not well agreed upon within the scientific community and we are not aware that the concentration of NADH has even been measured with individual fungal spores or pollen grains (Sivaprakasam et al., 2004; Hill et al., 2009).

This paper investigates the identity and properties of biogenic fluorophores that are most likely responsible for autofluorescence within FBAP. Understanding of the molecular origin of bioaerosol autofluorescence is critical to the development of and measurements with real-time FBAP instrumentation. Moreover a detailed understanding of commonly occurring fluorophores will aid the estimation of the selectivity that can be achieved by FBAP measurement. Some initial studies provide fluorescence spectroscopic data for different classes of PBAP, pure fluorophores and interferences (Campbell et al., 2005; Kopczynski et al., 2005; Wlodarski et al., 2006; Jeys et al., 2007; Hill et al., 2009; O'Connor et al., 2011). In this study we provide a synthesis of literature data as well as original laboratory measurements, designed to give a broad overview of intrinsic fluorophores most likely to be important within ambient aerosols. While subsets of information regarding intrinsic fluorescence of classes of biological molecules have been previously reviewed elsewhere (see Sec. 2), each from a certain perspective, the current synthesis comprehensively summarizes material relevant to atmospheric aerosol research for the first time. Fluorophores are characterized by their steady state fluorescence properties and discussed in relation to a collection of current fluorescent bioaerosol detectors. Moreover, we estimate the relative importance of these fluorophores to atmospheric measurement, using fluorescence characteristics and atmospheric abundance as primary metrics. We also provide fluorescent EEM maps measured with a bench-top spectrofluorometer both for a variety of bulk solid-, suspended-, and solutionphase biological fluorophores and for selected non-biological 
compounds which could be considered as important interfering species for FBAP detection and quantification in certain ambient situations. This combination of information will be crucial in the future investigation of the fluorescent properties of standard bioaerosol particles in the laboratory under varied environmental conditions.

\section{Literature synthesis}

Many fields of science have utilized intrinsic fluorescence for study of biological molecules. The following section serves as an overview of existing knowledge about biological fluorophores that have potential atmospheric relevance. Several existing reviews have collected similar information from the perspective of disparate scientific fields such as biology (Billinton and Knight, 2001; Roshchina, 2003, 2005), medical science (Koenig and Schneckenburger, 1994; RichardsKortum and SevickMuraca, 1996; Ramanujam, 2000; DaCosta et al., 2003) and defense research (Kopczynski et al., 2005; Wlodarski et al., 2006; Pan et al., 2010). Most of these overviews, however, are shorter and less exhaustive. For this reason we provide in this section a synthesis of literature values and knowledge that represent an extensive collection of fluorophores specifically relevant to atmospheric PBAP detection. Table 1 gives a summary of key parameters for each compound and a short characterization of the major fluorophore groups is given in the corresponding text section. Information about $\lambda_{\mathrm{ex}}$ and $\lambda_{\mathrm{em}}$ are based on data from different studies which are merged here into representative spectral ranges. Depending on data availability and measurement conditions, this can be seen as a general, but not exhaustive, characterization of the fluorescence properties of key fluorophores and classes. Moreover, as a first approach for general orientation the relevance of individual fluorophores for FBAP detection is estimated based on its fluorescence properties (category 1) and atmospheric abundance (category 2). Fluorophores were ranked as highly relevant if they show both intense fluorescence emission and are considered by the authors to be very abundant in PBAP. Fluorophores were ranked with medium relevance if one of the two categories was rated high and the other was considered weak/low. Low relevance means molecules are weakly fluorescent and show rare occurrence. While the terms listed here are uncertain and potentially contentious, we feel this language provides a qualitative means for discussion.

\subsection{Group I - amino acids}

Amino acids are the basic structural constituent of proteins and peptides in all organisms. Three amino acids with aromatic side chains - tryptophan (Trp), tyrosine (Tyr) and phenylalanine (Phe) - are known to UV or blue visible fluorescent emission when excited in the UV range of the electromagnetic spectrum. All three are relatively rare in proteins (Trp: $1.1 \%$ of total amino acid groups, average; Tyr: $3.5 \%$; Phe: $3.5 \%)^{1}$, though still structurally important and of sufficient concentration to cause the omnipresent intrinsic fluorescence of proteins (Klapper, 1977; Creed, 1984a,b). However, it is known that tryptophan is the dominant fluorophore in proteins (causing approx. $90 \%$ of the signal), due to a relatively high quantum yield $(\Phi=0.13-0.20$, depending on microenvironment) and efficient (non-radiative) resonance energy transfer (RET) from phenylalanine and tyrosine to tryptophan (energy transfer quenching of Phe and Tyr fluorescence). Tyrosine is the major source of fluorescence for proteins and peptides without tryptophan, whereas phenylalanine is of only minor importance in all cases due to its low quantum yield $(\Phi=\sim 0.02)$ and efficient RET. Consequently, in most cases emission of fluorescence from proteins is dominated by tryptophan, though specific properties are also highly sensitive to the protein's molecular environment (i.e. conformational transitions, substrate binding, denaturation which leads to variations in emission maximum and quantum yield between proteins) (Dalterio et al., 1987; Permyakov, 1993; Lakowicz, 1999; Ladokhin, 2000).

\subsection{Group II - coenzymes and vitamins}

This group summarizes fluorophores that can be assigned to coenzymes (free or bound to an enzyme) and vitamins. They frequently exhibit fluorescence due to heterocyclic aromatic rings within their molecular structures. The major classes of fluorescent coenzymes are the pyridines, pteridines, pyridoxines and structurally related flavins, among which NAD $(\mathrm{P}) \mathrm{H}$ and flavins are most frequently studied (Dalterio et al., 1987; Lakowicz, 1999; Wlodarski et al., 2006).

Two pyridine nucleotides, nicotinamide adenine dinucleotide (NADH) and nicotinamide adenine dinucleotide phosphate (NADPH), are well known fluorescent coenzymes which are often utilized as intrinsic fluorescent probes in various scientific fields (Bigio and Mourant, 1997; Huang et al., 2002). While similar in structure, the two coenzymes appear in different biochemical mechanisms. NADH is the universal coenzymatic redox carrier in the energy metabolism of cells, whereas NADPH is a ubiquitous reductant in biosynthesis processes (Klingenberg and Bucher, 1960; Michal, 1999; Voet and Voet, 2004). In contrast to the oxidized form $\mathrm{NAD}(\mathrm{P})^{+}$, only the reduced form $\mathrm{NAD}(\mathrm{P}) \mathrm{H}$ is fluorescent and can be utilized for an optical assessment of cell metabolic status (Eng et al., 1989; Li et al., 1991; Farabegoli et al., 2003; Wos and Pollard, 2006). Excitation occurs either at $\sim 340 \mathrm{~nm}$ (direct excitation of the coenzyme) or at $\sim 295 \mathrm{~nm}$ (light absorption by protein and RET to bound NAD(P)H) (Li and Lin, 1996). NADH and NADPH both show an emission signal at $\sim 460 \mathrm{~nm}$ and thus cannot be spectrally separated. For this reason the two molecules are often represented

\footnotetext{
${ }^{1}$ Based on sequences from 207 non-related proteins.
} 


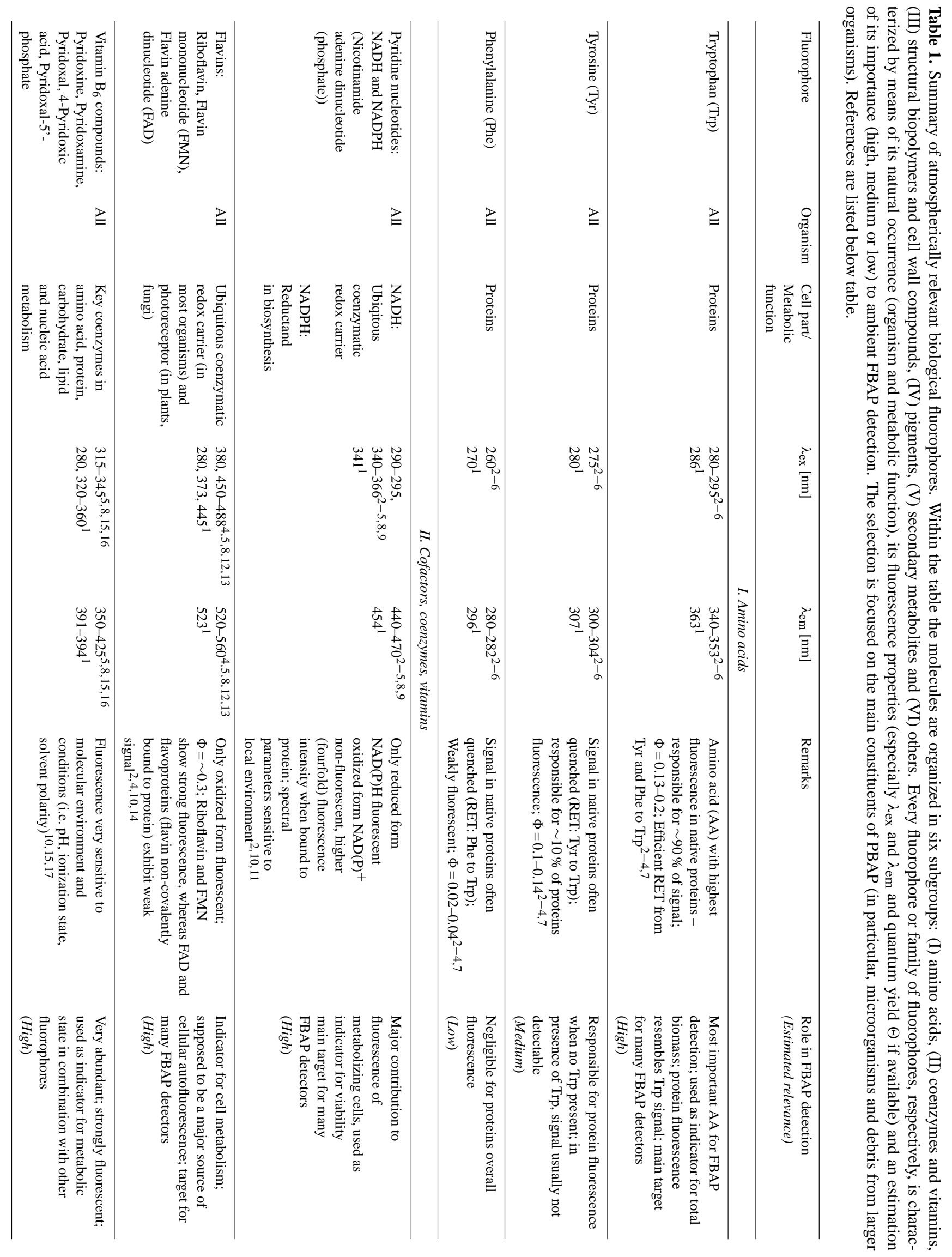




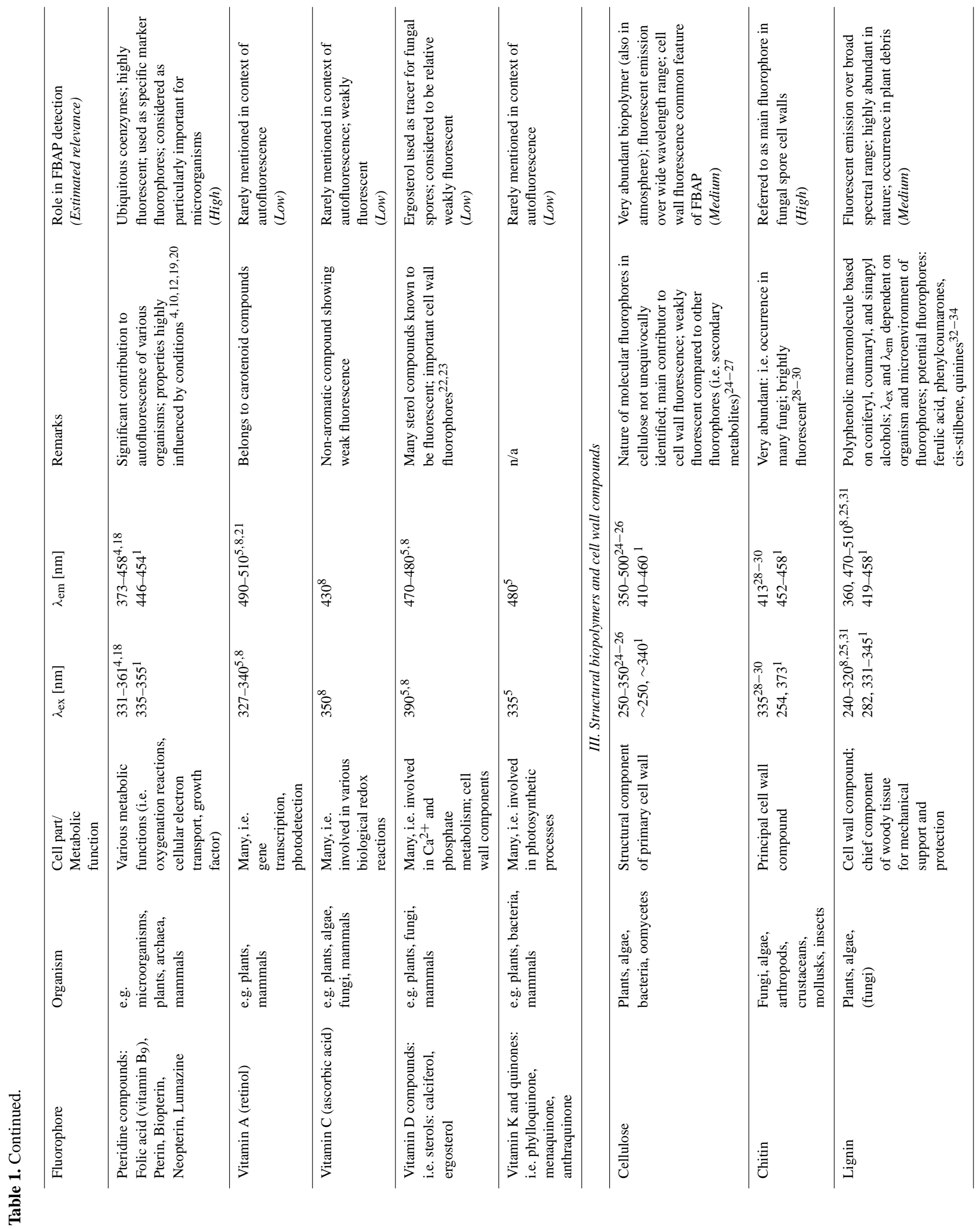




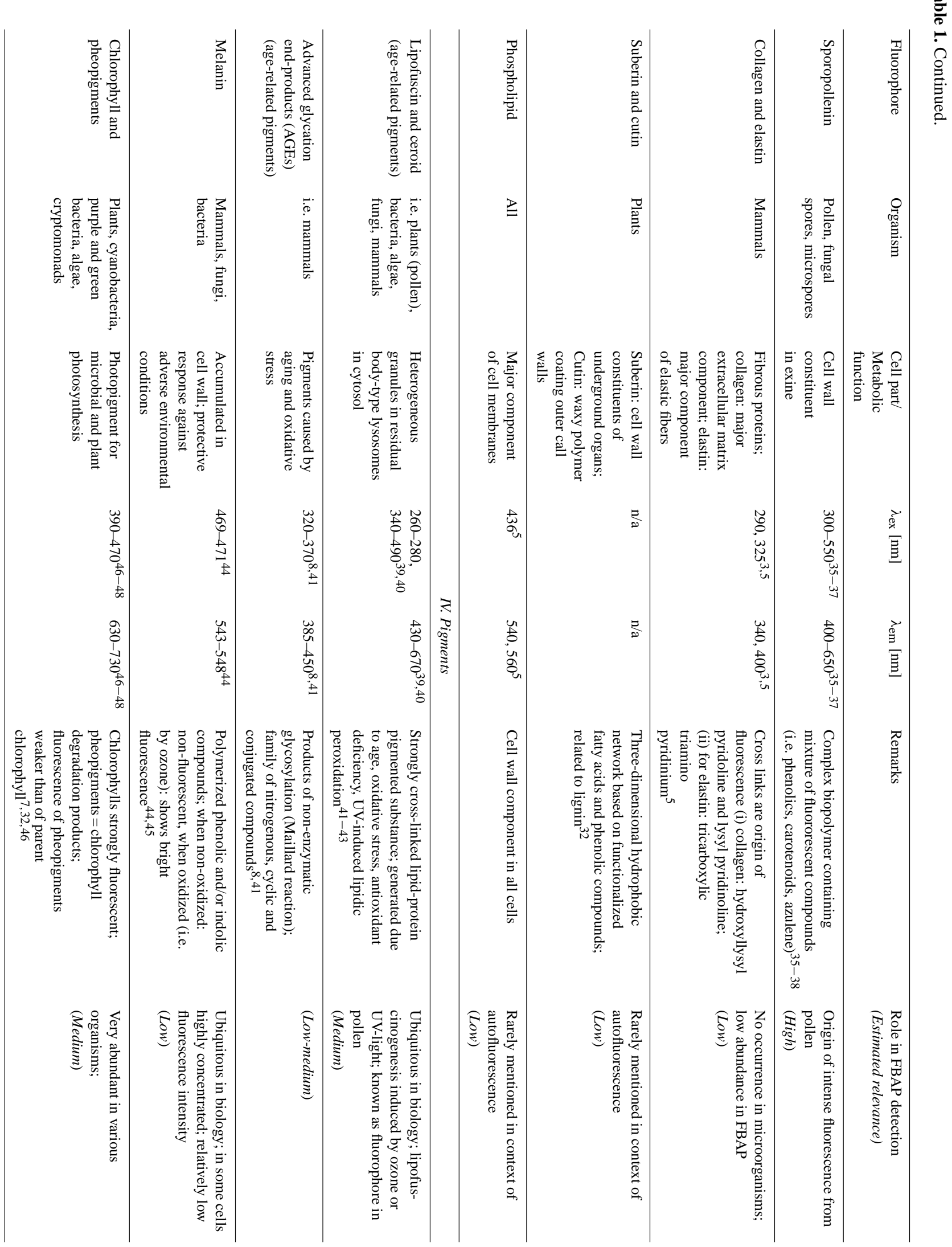




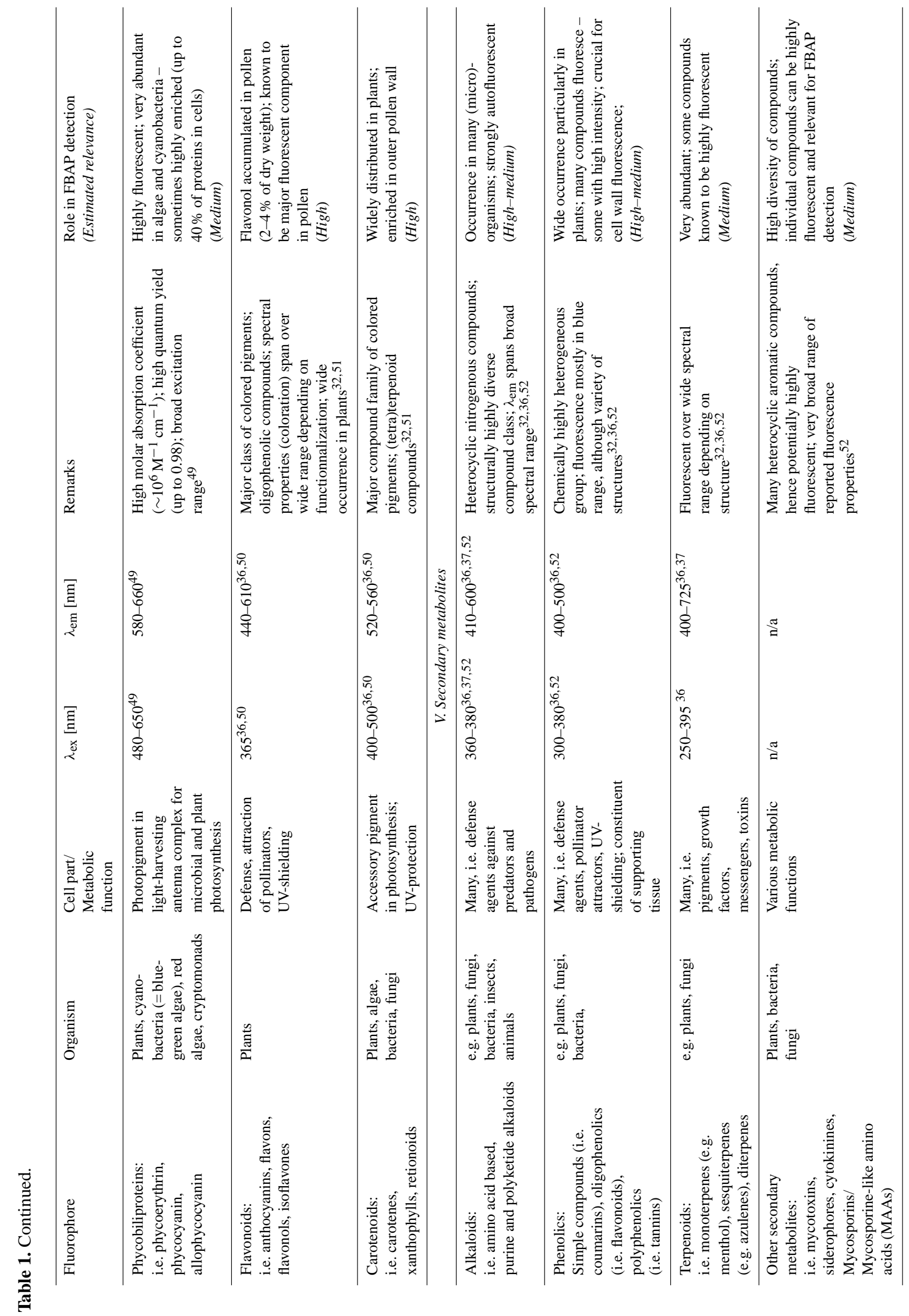




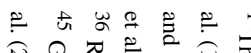

爰

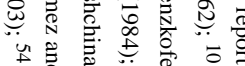

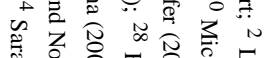

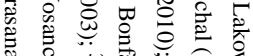

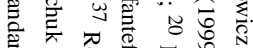

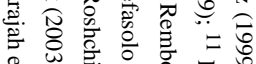

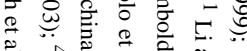

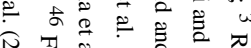

苍震产

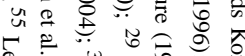

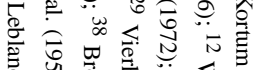

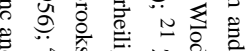

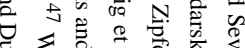

क人

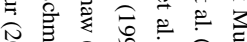

过产

u.

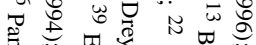

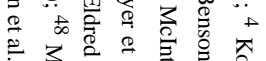

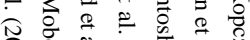

त्षे

क ิे

论

\& 8 क क्ष

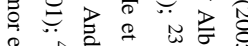

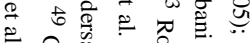

กิ๊

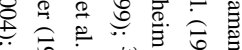

山ै

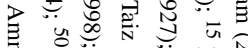

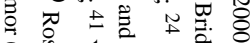

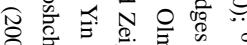

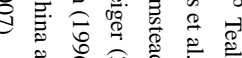

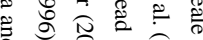

ว

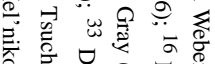

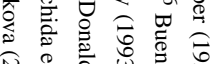

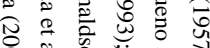

$8 \cong 0$

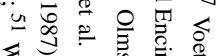

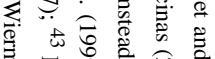

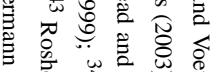

ॠ

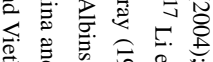

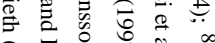

可不

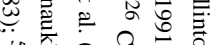

出

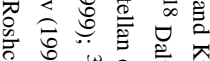

.

类

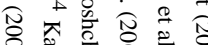

क्र

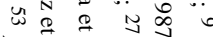

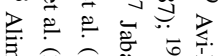

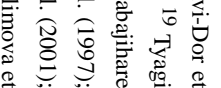

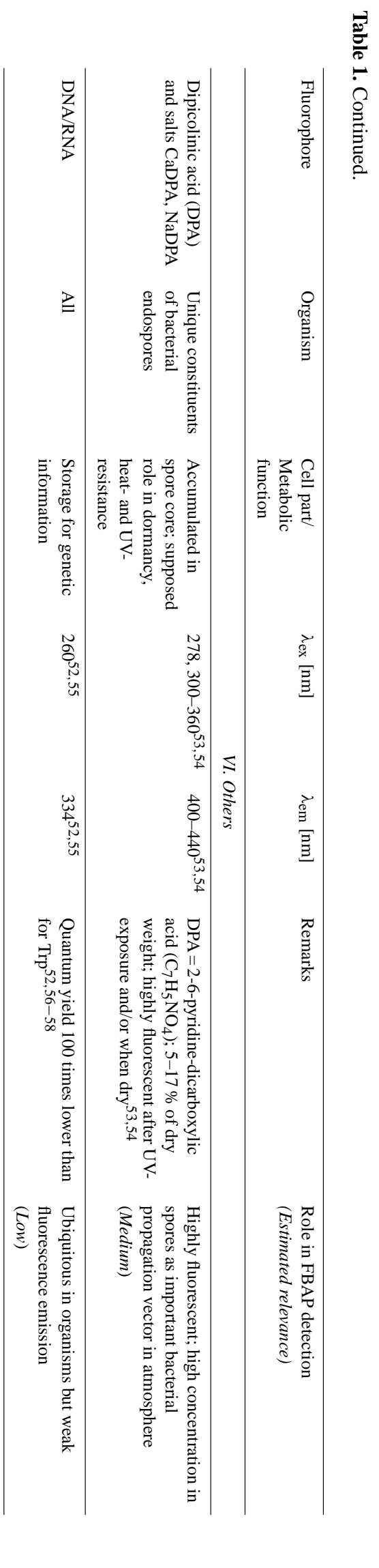


by a short-hand $\mathrm{NAD}(\mathrm{P}) \mathrm{H}$ form, referring to both molecules at once. It has been shown that the fluorescence contribution of NADH dominates that of NADPH, due to differences in cellular concentration and fluorescence characteristics. Furthermore the NADH signal is highly influenced by the metabolic status whereas the weaker NADPH signal is rather constant (Vishwasrao et al., 2005). The excited electronic state is quenched by two mechanisms: collisional deactivation and stacking of the fluorescent nicotinamide ring to the adenine moiety. The extent of quenching is decreased when $\mathrm{NAD}(\mathrm{P}) \mathrm{H}$ is bound to a protein, thus explaining the fourfold increase in fluorescence intensity as compared to free $\mathrm{NAD}(\mathrm{P}) \mathrm{H}$ in solution ( $\mathrm{Li}$ and $\mathrm{Lin}, 1996)$. Because of its links to active cell metabolism, NAD(P)H has often been used in the search for viable airborne microorganisms (i.e. Hairston et al., 1997; Bundke et al., 2010). Cell death is accompanied by NADH and NADPH depletion within the temporal range of hours $(2-10 \mathrm{~h})$ depending on various intracellular processes and extracellular conditions (Petit et al., 2001; Liang et al., 2007).

Riboflavin (vitamin $\mathrm{B}_{2}$ ) is the precursor for both cofactors flavin mononucleotide (FMN) and flavin adenine dinucleotide (FAD), which are prosthetic groups of flavoenzymes (Benson et al., 1979). Flavins are ubiquitous redox carriers in the energy metabolism of all organisms and act also as photoreceptors in plants and fungi (Galland and Senger, 1988; Billinton and Knight, 2001). In contrast to NAD(P)H, only the oxidized form of flavins is fluorescent and shows light emission at $\sim 525 \mathrm{~nm}$ when excited at $\sim 450 \mathrm{~nm}$, although excitation has also been observed at $\sim 280 \mathrm{~nm}$ and $\sim 380 \mathrm{~nm}$ (Hill et al., 2009). It is known that riboflavin and FMN show intense fluorescence, whereas FAD and especially flavoproteins exhibit only a weak fluorescence signal (Albani et al., 1999). Flavins are also connected to the metabolic status of cells, but at different rates than other conenzymes. Accordingly it has been suggested that the ratio of fluorescence emission of $\mathrm{NAD}(\mathrm{P}) \mathrm{H}$ to flavins can be used as indicator for the cellular metabolic rate (Chance et al., 1979; Siano and Mutharasan, 1989; Heikal, 2010).

Vitamin $\mathrm{B}_{6}$ acts as precursor for the coenzyme pyridoxine and related compounds (i.e. pyridoxal 5'-phosphate, pyridoxamine 5'-phosphate). Pyridoxine and related coenzymes are required by many enzymes that are involved in amino acid, protein, carbohydrate, lipid and nucleic acid metabolism in all organisms (Martell, 1989; Voet and Voet, 2004). Pyridoxine compounds comprise a substituted pyridine ring as structural fluorophore and its spectral characteristics are highly sensitive to its molecular environment (i.e. $\mathrm{pH}$, ionization state, solvent polarity). Accordingly fluorescence occurs in a relatively broad spectral ranges depending on the conditions ( $\lambda_{\mathrm{ex}}=315-345 \mathrm{~nm}, \lambda_{\mathrm{em}}=350-425 \mathrm{~nm}$ ) (Bridges et al., 1966; Bueno and Encinas, 2003). Pyridoxine compounds are key metabolites and along with $\mathrm{NAD}(\mathrm{P}) \mathrm{H}$ and flavins have been commonly utilized as indicators for metabolic activity, often in combination with other intrinsic fluorophores (i.e. Trp, NAD $(\mathrm{P}) \mathrm{H})$ (Siano and Mutharasan, 1989; Li et al., 1991; Heikal, 2010).

Pteridine compounds are ubiquitous within most organisms and as a group are comprised by: folic acid (vitamin $\mathrm{B}_{9}$ ), pterins, and lumazines, among others. They are involved in various biochemical processes, such as oxygenase reactions, single carbon transfer reactions and cellular electron transport. The bicyclic ring system is structurally related to purine and exhibits strong fluorescent emission (Rembold and Gyure, 1972). Pteridines have been considered as responsible for significant autofluorescence within bacterial cells (Dalterio et al., 1987; Kopczynski et al., 2005; Wlodarski et al., 2006), fungi (Hohl et al., 1992; Galland and Tolle, 2003) and other microorganisms (Galland et al., 1990; Uchiyama et al., 1997). Pteridines emit fluorescence peaking at $\sim 450 \mathrm{~nm}$ when excited at $\sim 350 \mathrm{~nm}$, though this is partially dependent on environmental conditions such as $\mathrm{pH}$ and ionization state (Dalterio et al., 1987; Tyagi and Penzkofer, 2010).

Other vitamins, such as vitamin $\mathrm{A}, \mathrm{C}, \mathrm{D}$ and $\mathrm{K}$, are sometimes mentioned in the context of cellular fluorescence (Billinton and Knight, 2001; Ramanujam, 2006). However, most of these are considered to comprise only minor contributions, due to low concentration, weak fluorescent emission, or both. In particular ergosterol (sterol compound, precursor for vitamin D) can be found in the cells wall of fungi and yeasts and has often been used as a tracer for fungal spores (Lau et al., 2006; Burshtein et al., 2011). Ergosterol and other sterols are known to fluoresce, though usually weakly, and this has been utilized in some cases for their detection (e.g. This work, Fig. 21; Rosenheim, 1927; McIntosh et al., 2008).

\subsection{Group III - structural biopolymers and cell wall compounds}

In addition to fluorophores which actively participates in cellular metabolism, various structural compounds also emit fluorescent radiation. The biopolymers cellulose, chitin, lignin and sporopollenin are structural compounds crucial to many microorganisms and are abundant within the atmosphere (Kunit and Puxbaum, 1996; Winiwarter et al., 2009). The protein polymers elastin and collagen also exhibit fluorescent emission, however, they are regarded as of minor importance due to their absence in microorganisms.

Cellulose $(\beta(1,4)$-linked homopolymer of D-glucose) is one of the most abundant organic compounds in nature and, in particular, is an essential constituent in the cell wall of various organisms (such as bacteria, fungi, algae, plants) (Cannon and Anderson, 1991; Niklas, 2004; Voet and Voet, 2004). Cellulosic materials exhibit fluorescence over a broad spectral range with an emission maximum at $\sim 420 \mathrm{~nm}$ and efficient excitation in the UV range (250-350 nm) (Olmstead and Gray, 1993, 1997; Castellan et al., 2007). The spectral properties of cellulose from different sources are well 
characterized, however the molecular origin of the fluorescence is still debated (Olmstead and Gray, 1993). The fluorescence of cellulose is known to be highly increased by phenolic residues (e.g. ferulic acid) (Roshchina, 2008).

Chitin $(\beta(1,4)$-linked homopolymer of $\mathrm{N}$-acetylglucosamine) is a highly abundant cell wall compounds which occurs in all fungi, various microorganisms and insects (Lenardon et al., 2010). It shows maximum fluorescent emission $\sim 410 \mathrm{~nm}$ and an excitation maximum $\sim 335 \mathrm{~nm}$ (Jabajihare et al., 1984). Several studies refer to chitin as a major fluorophore in fungal cell walls (Bonfantefasolo et al., 1990; Vierheilig et al., 1999; Dreyer et al., 2006).

Lignin is the chief compound in woody tissue and the most abundant polymer in nature, along with cellulose. It is a polyphenolic, branched, and disordered macromolecule derived by polymerization of monolignols in the cell wall of plants and algae (Donaldson, 2001; Boerjan et al., 2003). Lignin exhibits intense fluorescent emission of blue and green light when excited by radiation in the UV or blue spectral range, respectively (Harris and Hartley, 1976; He et al., 1999; Donaldson, 2001). It is assumed that light is absorbed by a number of chromophores (light-absorbing molecules) followed by intramolecular energy transfer to certain emission sinks (i.e. phenylcoumarone, stilbene) (Olmstead and Gray, 1997; Albinsson et al., 1999). In general, the fluorescence properties of these structural compounds are rather undefined and distributed over a broad spectral range, depending on organism and conditions (Billinton and Knight, 2001).

Sporopollenin is a rigid and complex biopolymer comprising a main constituent of the outer cell wall (exine) of pollen (Brooks and Shaw, 1978). Its intense fluorescent emission over a broad spectral range is caused by a mixture of different fluorophores, such as phenolic compounds $\left(\lambda_{\mathrm{em}}=\sim 460 \mathrm{~nm}\right)$, carotenoids $\left(\lambda_{\mathrm{em}}=\sim 530 \mathrm{~nm}\right)$, azulene $\left(\lambda_{\mathrm{em}}=\sim 450 \mathrm{~nm}\right)$, anthocyanin $\left(\lambda_{\mathrm{em}}=\sim 460\right.$ and $\left.620 \mathrm{~nm}\right)$ and other compounds (Roshchina et al., 1997, 2003, 2004). However, the exact chemical composition of sporopollenin, including its fluorescence properties, is not well known.

The structural proteins collagen and elastin are important fluorophores within mammalian tissue which are frequently used for fluorescence-based tissue investigation. Both show similar fluorescent properties, respectively: $\lambda_{\mathrm{ex}}=\sim 325 \mathrm{~nm}$ and $\lambda_{\mathrm{em}}=\sim 400 \mathrm{~nm}$ (Billinton and Knight, 2001; Ramanujam, 2006). Due to their exclusive occurrence in mammalian tissues, however, these molecules are not expected to bare much significance on atmospheric FBAP.

\subsection{Group IV - pigments}

Two compound classes are summarized as fluorescent pigments in the following section: age-related pigments (i.e. lipofuscin, ceroid and melanin) and pigments that are involved in photoreceptor, photosynthesis and light harvesting processes (i.e. (bacterio)chlorophylls, phycobiliproteins, flavonoids and carotenoids).

The following intracellular and extracellular compounds are usually summarized as age related pigments: lipofuscin, ceroid, advanced glycation end-products (AGEs) and age pigment-like fluorophores (APFs). The formation of these yellow-brown pigments is based on oxidation and peroxidation of lipids, proteins, nucleic acids, carbohydrates and other biomolecules, followed by cross-linking of the secondary oxidation products (particularly unsaturated carbonyls) with amino compounds (i.e. primary amines, amino acids). The generated fluorophores are mainly nitrogeous conjugated and cyclic compounds and polymers (Tsuchida et al., 1987; Yin, 1996). Fluorescent emission has been observed in a broad spectral range, when excited by UV or blue light. Usually fluorescent emission of cellular age related pigments is located between 450 and $640 \mathrm{~nm}$, depending on the identity of the fluorophores, cellular environment and concentration (Eldred et al., 1982; Andersson et al., 1998).

Melanins are dark-colored hydrophobic pigments of high molecular weight which are assumed to consist of polymerized phenolic and indolic compounds. They are ubiquitous in nature and occur in various organisms, particularly fungi and bacteria have been found to show a high melanin content which is associated with microbial pathogenesis (Gomez and Nosanchuk, 2003; Nosanchuk and Casadevall, 2003). Compared to the other age-related pigments, melanin is regarded to show only a relatively weak fluorescence, but it has been shown that oxidation significantly increases fluorescence with a emission maximum at $\sim 540 \mathrm{~nm}$ when excited at $\sim 470 \mathrm{~nm}$ (Kayatz et al., 2001).

Fluorescent light emission from tetrapyrrolic compounds (i.e. protoporphyrin IX, chlorophylls, phycobilins) is well known and utilized in various applications (i.e. Lichtenthaler et al., 1986). Photosynthetic chlorophyll pigments such as chlorophyll- $a, b, c$ and $d$ in plants, many algae and cyanobacteria show fluorescent emission $\sim 650 \mathrm{~nm}$. Pheopigments are chlorophyll degradation products obtained by acidification which show fluorescent emission (630$730 \mathrm{~nm}$ ) with weaker intensity than the parent chlorophylls (French et al., 1956; Welschmeyer, 1994; Moberg et al., 2001). Another important class of fluorescent tetrapyrrolic pigments are phycobiliproteins and bilins as their prosthetic groups. They are known to show intense fluorescent emission of red light $(580-660 \mathrm{~nm})$ with high quantum yields (up to 0.98 ) (Glazer, 1994).

Carotenoids and flavonoids comprise the most important colored pigments in plants (Mantoura and Llewellyn, 1983). Flavonoids are polyphenolic and carotenoids are terpene compounds. Because of their pronounced fluorescence characteristics and importance in FBAP detection, they are each listed here as independent fluorophore classes. Both pigments are known to be enriched in certain plant parts, particularly in pollen $\left(\mu \mathrm{g} \mathrm{kg}^{-1}\right)$, constituting a main origin of 
pollen autofluorescence (Roshchina and Karnaukhov, 1999, 2003; Taiz and Zeiger, 2010).

\subsection{Group V - secondary metabolites}

In addition to the given metabolites and intermediates (i.e. amino acids, sugars, nucleotides) in the primary metabolism (growth and development) of organisms, myriads of highly structurally diverse organic compounds, called secondary metabolites, are known, but which have no direct role in basic anabolic or catabolic processes. They are distinctive products with relatively narrow distribution among small groups of species and are active players in highly specialized metabolic processes of survival and competition: i.e. mycotoxins in fungi, terpenoids as attractants for pollinators, or metal-chelating siderophores in bacteria (Vining, 1990; Theis and Lerdau, 2003; Keller et al., 2005; Taiz and Zeiger, 2010). Secondary metabolites usually comprise complex chemical structures, often with conjugated heterocycles containing oxygen atoms $(\mathrm{O})$ or nitrogen atoms $(\mathrm{N})$, or both. Many tend to be autofluorescent and are known to show a significantly higher intensity compared to structural fluorophores in cell walls and primary metabolites (Roshchina, 2003, 2008). In the following paragraph main classes of secondary metabolites and their autofluorescence properties (if known) are discussed.

Alkaloids are one of the most diverse groups of secondary metabolites and occur in plants, fungi, bacteria, insects and other organisms, though every species shows a specific genetically determined alkaloid pattern. Most of these compounds serve as defense agents against predators and pathogens. Alkaloids are defined as cyclic compounds containing $\mathrm{N}$ in low oxidation states and can be subdivided based on their molecular origin into four groups: alkaloids based on amino acids, purine alkaloids, aminated terpenes and polyketide alkaloids (Roberts, 1998). The high structural diversity is reflected into highly diverse spectral properties. According to Roshchina $(2003,2005)$ a wide spectral range $(410-600 \mathrm{~nm})$ of fluorescent emission is covered by plant alkaloids. For UV excitation $(360-380 \mathrm{~nm})$ emission in the shorter wavelength range $(410-520 \mathrm{~nm})$ has been found for structurally smaller alkaloids (e.g. atropine) whereas larger compounds (e.g. sanguinarine) exhibit further red-shifted emission $(585-600 \mathrm{~nm})$.

Phenolic compounds comprise a large variety of chemically heterogeneous substances including simple molecules (e.g. benzoic acid derivatives, coumarins), oligophenolics (e.g. flavonoids) and complex polyphenolics (e.g. lignin, tannins). The unifying chemical feature is a multiple hydroxyl functionalization of conjugated and non-conjugated aromatic structures. They serve as UV shielding, defense against pathogens and mechanically supportive tissue. Many phenolics are well known fluorophores which usually emit blue fluorescence light (400-500 nm) when excited in the UV range (Roshchina, 1997).
Terpenes (or tepenoids) comprise a diverse class of lipophilic secondary metabolites synthesized by plants. Structurally based on isoprene $\left(\mathrm{C}_{5}\right)$ units, this group includes monoterpenes $\left(\mathrm{C}_{10}\right.$ compounds), sesquiterpenes $\left(\mathrm{C}_{15}\right)$, diterpenes $\left(\mathrm{C}_{20}\right)$ and other even larger compounds. They play important roles in various metabolic processes for examples as accessory pigments in photosynthesis (carotenoids, $\mathrm{C}_{20}$ ), deterrent toxins (pyrethroids, $\mathrm{C}_{10}$ ) or insect repellents (monoand sesquiterpenes) (Theis and Lerdau, 2003; Taiz and Zeiger, 2010). For several monoterpenes Roshchina (2003) reports fluorescent emission in the blue range of the electromagnetic spectrum $(405-430 \mathrm{~nm})$ when excited with UV light (310-380 nm). For larger terpenes fluorescent emission occurs red-shifted, depending on the size of the conjugated $\pi$-bond system.

In addition to the previously mentioned large classes of secondary metabolites several other families of compounds such as mycotoxines, siderophores, quinones and mycosporin-like amino acids (MAAs) are known to autofluoresce, although details are in most cases not yet understood. In certain cases these compounds can be relevant for the autofluorescence of an organism even in low concentrations. In general secondary metabolites can be considered as a highly structurally diverse class of compounds comprising autofluorescent emission over a wide spectral range. Depending on their occurrence and concentration in certain species they can act as important or even dominant fluorophores.

\subsection{Group VI - other fluorophores}

Fluorophores that do not fit in the previous groups are summarized here. The most important compounds here are DNA and RNA as well as dipicolinic acid (DPA). The genetic information of all organisms is stored in the sequence of purin and pyrimidine bases in deoxyribonucleic acid (DNA). In the expression of genes and in the biosynthesis of peptides and proteins ribonucleic acid (RNA) is responsible for the information transfer from the genome to the proteome. The nucleic acids DNA and RNA are known to be fluorescent due to their constitutive nitrogenous and heterocyclic bases adenine, cytosine, guanine and thymine. Different studies report about DNA and RNA autofluorescence in microorganisms. When excited at $260 \mathrm{~nm}$ DNA fluorescence can be observed at 330 $335 \mathrm{~nm}$, although the signal is merged with the protein emission peak (e.g. Leblanc and Dufour, 2002; Roshchina, 2008). Biological aromatic molecules tend to be fluorescent due to energetically accessible $\pi-\pi^{*}$ transitions, however, some heterocyclic aromatic compounds (i.e. the bases of DNA and RNA) are known to be very weakly fluorescent (Pan et al., 2009). The quantum yield of DNA/RNA is 100-times lower than tryptophan (Leblanc and Dufour, 2002; Estes et al., 2003; Ammor et al., 2004, 2007), however, and thus the overall relevance of DNA autofluorescence is considered to be negligible. 
Dipicolinic acid (DPA or 2-6-pyridine-dicarboxylic acid) and its salts are synthesized during bacterial spore formation and enriched in the spore core ( $>10 \%$ of dry weight), where these compounds are assumed to be involved in affecting spore dormancy, heat resistance, and UV radiation protection (Paidhungat et al., 2000; Slieman and Nicholson, 2001). Medium fluorescence is observed for pure DPA in the dry state which is increased by UV-light exposure. The emission occurs around $440 \mathrm{~nm}$, with an excitation maximum at $360 \mathrm{~nm}$. The calcium salt CaDPA is also known to be fluorescent with peak emission at approximately $410 \mathrm{~nm}$, when excited between 280 and $340 \mathrm{~nm}$ (Alimova et al., 2003; Sarasanandarajah et al., 2005). Since DPA occurs exclusively in bacterial endospores, it has been used as a spectral signature for spore detection (Bronk et al., 2000).

\subsection{Possible interfering, non-biological compounds}

Fluorescence is a widespread phenomenon common to a wide variety of chemical compounds and materials. As such it is not unique for biological materials, and aerosol of both anthropogenic and natural origin may also show emission of fluorescent radiation. This must be considered when performing fluorescence measurements on atmospheric samples, because certain non-biological compounds have the potential to cause positive fluorescence measurement artifacts and an overestimation of actual FBAP concentrations. We discuss here a selection of possible interferences in this context: (I) humic-like substances (HULIS), (II) secondary organic aerosols (SOA), (III) minerals/mineral dust, (IV) polycyclic aromatic hydrocarbons (PAH) and (V) soot. The following section briefly characterizes the fluorescence properties of each class, but is not represented in Table 1.

HULIS is a complex mixture of poorly defined heterogeneous compounds formed by biological material broken down through natural decay mechanisms and after subsequent atmospheric oxidation (Andreae and Gelencser, 2006; Graber and Rudich, 2006). It is terrestrially ubiquitous, but also constitutes an important subset of the organic aerosol fraction. While not chemically identical, humic and fulvic acids are generally considered to be appropriate HULIS surrogates. Various studies have investigated the fluorescence properties of humic and fulvic acids by means of EEMs. In particular the soluble fraction, referred to as dissolved organic matter (DOM), has been investigated in natural waters from rivers and oceans (Coble, 1996; Hudson et al., 2007) as well as rain and fog droplets (Duarte et al., 2004; Kieber et al., 2006; Birdwell and Valsaraj, 2010). Because humic-like material extracted from complex natural matter is not chemically pure it contains a mixture of many fluorophores. It has been shown that EEMs of DOM show two types of fluorescence modes: for humiclike and protein-like fluorescence, respectively. Humiclike fluorescence has been observed in three characteristic spectral positions $\left(\lambda_{\text {ex }} / \lambda_{\text {em }}\right)$ at: (i) $237-260 / 380-460$ (humic-like, UV excitation), (ii) 300-370/400-500 (humiclike, visible excitation), (iii) 312/380-420 (marine humiclike). Protein- or amino acid-like fluorescence, however, occurs at 275/310 (tyrosine-like) and at 275/340 (tryptophanlike) (Coble, 1996; Hudson et al., 2007; Muller et al., 2008). Occurrence, spectral properties, and relative intensity of these five modes are highly dependent on molecular identity and chemical properties of the sample, however, and vary from sample to sample. It is reported that the fluorescence spectra, particularly EEMs, of humic and fulvic acids provide chemical and structural information such as conformation and functional groups (Chen et al., 2003), molecular weight (Stewart and Wetzel, 1980), aromatic character (Miano et al., 1988) and oxidation state (Klapper et al., 2002). HULIS isolated from aerosols or cloud water tends to show farther blue-shifted fluorescence when compared to terrestrial samples and thus is more similar to marine humic-like material (e.g. Krivacsy et al., 2001; Duarte et al., 2004). This may indicate aerosol HULIS contains a lower molecular weight and a smaller content of aromatic and conjugated $\pi$-bond structures compared with terrestrial HULIS (Graber and Rudich, 2006).

Secondary organic aerosol (SOA) is also an important constituent of atmospheric particulate matter, dominating submicron aerosol in many environments and also capable of condensing as a liquid layer onto larger particles (Pöschl, 2005; Jimenez et al., 2009; Pöschl et al., 2010). SOA forms as a result of the atmospheric oxidation of ubiquitous volatile organic compounds (VOCs) generating myriads of differently functionalized organic molecules. Bones et al. (2010) investigated the autofluorescence properties of lab-generated limonene and $\gamma$-terpinene SOA which exhibits strongly increased fluorescent emission when aged in the presence of ammonium compounds or amino acids. They found four major fluorescence modes (280/420, 300/360, $340 / 440,425 / 490 \mathrm{~nm}$, respectively) similar to the autofluorescence characteristics of HULIS. In particular this study indicates that nitrogen-containing SOA could be an important source of autofluorescence within certain SOA. In a related study Chang et al. (2010) found fluorescent emission within $325-425 \mathrm{~nm}$ when excited at $280 \mathrm{~nm}$ for photooxidation products of various phenolic compounds.

Mineral dust is also a major constituent of the global atmospheric aerosol, occurring in both fine and coarse mode and dominating total particle mass concentrations at locations worldwide (Gillette and Walker, 1977; Andreae and Rosenfeld, 2008; Monks et al., 2009). The photoluminescence of minerals is a well known phenomenon, and this allows the analysis of the presence and identity of so-called luminescence centers within given minerals (i.e. transition metal cations, rare-earth cations, biological impurities, trapped electron-hole pairs). A variety of different naturally occurring minerals (e.g. silicate, carbonate, phosphate and sulfate minerals) have been found to show clearly resolved, narrow emission modes at $\sim 500$ and $\sim 700 \mathrm{~nm}$ when excited at 
different wavelengths, for example 266 or $355 \mathrm{~nm}$, in which particularly transition metal cations such as $\mathrm{Mn}^{2+}, \mathrm{Eu}^{2+}$ and/or $\mathrm{Ti}^{3+}$ originate these characteristic emission bands (Bozlee et al., 2005). The lifetime of these processes have been found to span a wide range from nanoseconds $\left(10^{-9} \mathrm{~s}\right)$ to milliseconds $\left(10^{-3} \mathrm{~s}\right)$, indicating the occurrences of both fluorescence and phosphorescence processes (Reisfeld et al., 1996; Gaft et al., 2001; Bozlee et al., 2005). The luminescence processes in minerals are not yet well understood due to complex atomic interactions within the crystal structures. However, because many isolated minerals have been shown to be capable of fluorescent emission they may contribute to fluorescence of certain types of dust within atmospheric aerosols and, therefore, should be considered as possibly introducing interference for FBAP detection in some situations. In many cases the timescale of emission (i.e. for phosphorescence) may be longer than detectable by online instrumentation, however, and so would not contribute significantly to detected FBAP numbers in these cases (e.g. Reisfeld et al., 1996).

PAHs are omnipresent in the environment and are known to have severe impacts on human health (e.g. Dix and Marnett, 1983; Nielsen et al., 1984). In the atmosphere they can occur primarily in the gas-phase as products of incomplete combustion (highly volatile 2-ring compounds, i.e. naphthalene), absorbed on organic aerosol particles such as soot, (low-volatile 5-ring compounds, i.e. benzo[a]pyrene) or as semi-volatile species present in both gas and particle phases (3- and 4-ring compounds, i.e. phenanthrene) (e.g. Finlayson-Pitts and Pitts, 2000; Slowik et al., 2007). LIF and a number of other methods have been utilized to indentify and quantify PAHs in atmospheric aerosols (e.g. Niessner and Krupp, 1991; Panne et al., 2000). Pure PAHs are known to be highly fluorescent (quantum yields up to 1.0$)$ over a wide spectral range (300-460/310-540). In the natural environment they usually occur as mixture of different compounds and produce complex EEMs (Kumke et al., 1995). PAHs are also known to be particularly enriched on the surface of soot particles from biomass burning and fuel combustion. When excited by strong laser light the mixture of PAHs in combustion aerosols can be analyzed and quantified (Aizawa and Kosaka, 2008, 2010). However, it has also been observed that fluorescent emission by PAH coatings on organic aerosols is weak due to efficient quenching by the bulk material (Lewitzka and Niessner, 1995; Panne et al., 2000).

\section{Materials and methods}

\subsection{Chemicals and materials}

Samples of humic acid $(2 \mathrm{~S} 101 \mathrm{H})$ and fulvic acid (1S101F) were purchased from International Humic Substance Standards (IHSS; St. Paul, MN, USA). Arizona test dust
(ISO 12103-1) was obtained from Powder Technology Inc (Burnsville, MN, USA). Kaolin was purchased from Sigma Aldrich (K7375). Ash was obtained from wood burning (spruce, specially designed wood burning facility). Diesel soot (SRM 2975) was purchased from National Institute of Standards and Technology (NIST; Gaithersburg, MD, USA). Biomass burning soot was obtained by burning a sample of spruce and directly sampling the black smoke on a clean glass cover slide held at approximately $10 \mathrm{~cm}$ away from the flame in direct flow of the smoke. Saccharomyces cerevisiae was purchased as baker's yeast from a local supermarket and used immediately (within one day). Solvents were obtained from Merck (Darmstadt, Germany). All other chemicals were purchased from Sigma Aldrich. All purchased chemicals were used as delivered.

\subsection{Fluorescence spectroscopy}

All fluorescence spectra were recorded on a LS 45 Luminescence Spectrometer (Perkin Elmer, Inc.; Waltham, MA, USA). The instrument is equipped with a pulsed xenon lamp, two Monk-Gillieson-type grating monochromators ${ }^{2}$, and a gated photomultiplier tube (PMT) detector. Wavelengthdependent variation in light source intensity $(I)$ was corrected by an internal reference light path with dedicated PMT. Measurements were initiated after a minimum of approximately $30 \mathrm{~min}$ of instrument warm-up time to ensure lamp stability. The instrument was operated using FL WinLab software (Perkin Elmer, Inc.) and its performance was controlled (every $\sim 10$ th spectrum analyzed) by means of a software validation utilizing Raman and Rayleigh signal positions as well as the signal-to-noise ratio. All spectra were recorded at a PMT voltage of $650 \mathrm{~V}$, a scan speed of $600 \mathrm{~nm} \mathrm{~min}^{-1}$, and using excitation and emission slit widths of $10 \mathrm{~nm}$ at room temperature. EEMs were recorded for excitation wavelengths from $230-650 \mathrm{~nm}$ ( $5 \mathrm{~nm}$ increments) and emission wavelengths from $270-700 \mathrm{~nm}(0.5 \mathrm{~nm}$ increments). To avoid detector saturation for highly fluorescent samples a blocking filter (Perkin Elmer, Inc.) was utilized to reduce the emission intensity. This filter is a metal plate with holes bored through to allow $1 \%$ of light to be transmitted, but without introducing wavelength-dependent effects. Spectral analysis was performed using Igor Pro (Wavemetrics, Inc.; Portland, OR, USA).

Samples were investigated in the solid (powder), solution, or suspension states. Solvated and suspended samples were placed in a $10 \times 10 \times 40 \mathrm{~mm}$ UV quartz cuvette (Hellma Analytics, Müllheim, Germany) and measured immediately (within $15 \mathrm{~min}$ ). The concentration of fluorophore within solution or suspension was deliberated low in order to avoid inner filtering and concentration-related quenching effects. For highly dilute samples the concentration is linearly correlated with fluorescence intensity according to the

\footnotetext{
${ }^{2}$ e.g. http://gratings.newport.com/information/handbook/chapter6.as
} 
Beer-Lambert law. Suspensions of insoluble materials were prepared by adding fluorophore analyte $\left(0.2-0.4 \mathrm{mg} \mathrm{ml}^{-1}\right)$ to phosphate-buffered saline (PBS) at pH 7.2. PBS was prepared from ultrapure water (MilliQ, 18.2 M $\Omega$ ) and purified by sterile filtration before use. A magnetic stirrer was utilized to stir the sample in the cuvette during the measurement to avoid sedimentation. Solutions of most soluble fluorophores were prepared in PBS, however, pyrene, naphthalene, phenanthrene and chlorophyll- $b$ were solvated in $n$ hexane due to their hydrophobicity. The concentration of analyte used was $3 \mu \mathrm{mol}^{-1}$, but was increased by a factor of 10 or 100 for weakly fluorescent samples until fluorescent emission was detectable. Background correction of solvated or suspended samples was performed by taking the difference of fluorescence spectra of solvent with and without sample.

Powdered materials were analyzed with a Front Surface Accessory for the spectrometer (Perkin Elmer, Inc.). With this technique several milligrams of powder were placed onto the black surface holder and placed as a vertical plane into the spectrometer such that the illumination angle shining horizontally onto the sample surface shows maximum fluorescence intensity. The illumination spot size on the samples was $\sim 60 \mathrm{~mm}^{2}$. For weakly fluorescent powders, which exhibited no clear emission peaks, fluorescence properties were qualitatively dominated by light leakage (e.g. NaCl, Fig. S6 in the Supplement) and appear as steep-walled valleys of emission between the 1st and 2 nd order elastic scattering lines. The magnitude of "emission" on the left and right of the 1st order scattering peak are similar, however, confirming that most of the signal in the fluorescence region is spurious. The magnitude of this effect correlated with the color of the sample powder, with white samples exhibiting a higher background than colored samples. This suggests that light absorption within the samples reduces internal reflection and mitigates the background effect. We, therefore, assume that all radiation arriving to the detector at wavelengths shorter than the incident wavelength is due either to stray background light, or light leakage past the monochromators. EEMs of dry powder samples were normalized by the intensity of light leakage in order to provide a comparable scale of fluorescence intensity across all solid samples. Often fluorescence spectra of this type are normalized to the height of the 1st order scattering peak, but this was not possible here, because the PMT was saturated at this wavelength for some samples. For each EEM, a constant normalization factor (NF) was determined by taking the mean of the measured light leakage intensity values along a line $40 \mathrm{~nm}$ above the center of the excitation line (as shown in Fig. S1 in the Supplement) and dividing the entire matrix by this NF. Doing so preserves all qualitative features within measured EEMs, but normalizes the absolute intensity of fluorescence for comparison. Each 1-D spectrum shown with single excitation wavelength (Fig. 6) was extracted from the normalized EEMs.

As a result of differing normalization procedure quantitative comparison of emitted fluorescence intensity between wet and dry samples is not possible by this technique, while qualitative features are consistent and comparable. Further details concerning the normalization procedure can be found in the supplement (Fig. S1 in the Supplement) along with examples of non-normalized spectra (Figs. S4 and S5 in the Supplement).

\subsection{Fluorescence microscopy}

The fluorescence microscopy images were taken on a BZ-9000 Fluorescence Microscope (Keyence, Inc., Osaka, Japan). The instrument was equipped with a super-highcompression mercury lamp $(120 \mathrm{~W})$ and a $2 / 3$-inch, 1.5 mega pixel monochrome CCD. The following fluorescence filters were used to take images in different spectral ranges: OP-66834 DAPI-BP $\left(\lambda_{\text {ex }}=360 / 20 \mathrm{~nm}, \lambda_{\text {Dichroic }}=400 \mathrm{~nm}\right.$, $\left.\lambda_{\text {Absorp }}=460 / 25\right), \quad$ OP-66836 GFP-BP $\left(\lambda_{\text {ex }}=470 / 20 \mathrm{~nm}\right.$, $\left.\lambda_{\text {Dichroic }}=495 \mathrm{~nm}, \lambda_{\text {Absorp }}=535 / 25\right)$, OP-66838 TexasRed $\left(\lambda_{\text {ex }}=560 / 20 \mathrm{~nm}, \lambda_{\text {Dichroic }}=595 \mathrm{~nm}, \lambda_{\text {Absorp }}=630 / 30\right)$. Filter specifications are represented as wavelength and peak width $(\lambda / \mathrm{FWHM})$.

\subsection{Ambient sampling}

Ambient samples of airborne particulate matter were taken using a single stage impactor (PIXE International Corp. Tallahassee, FL, USA; nozzle diameter $0.65 \mathrm{~mm}$, distance between nozzle and impaction plate $3 \mathrm{~mm}$, flow rate $11 \mathrm{~min}^{-1}$, cut-point $\sim 0.6 \mu \mathrm{m}$ ) (Russell et al., 2002). Samples were taken on the roof of the Max Planck Institute for Chemistry building on the university campus in Mainz, Germany. Sampling was performed on a clean round glass cover slide (diameter $15 \mathrm{~mm}$, thickness $0.13-0.15 \mathrm{~mm}$ ) and immediately used for microscopy investigation.

\section{Results and discussion}

\subsection{EEMs of pure biological standards}

Following on the summary presented in Table 1 we applied fluorescence spectroscopy to a selection of pure biological fluorophores, particularly those molecules that are considered to be most relevant within ambient PBAPs. Figure 2 shows EEMs for a selection of biological fluorophores, and spectra for further compounds can be found in Fig. S2 in the Supplement. The selection covers protein autofluorescence by means of all three fluorescent amino acids and two common proteins: bovine serum albumin (BSA) and ovalbumin (OVA). Coenzymes constitute a diverse class of highly fluorescent compounds and are represented by several examples (i.e. pyridoxine, NADPH, folic acid and riboflavin). The major biopolymers are represented by cellulose and chitin as well as ferulic acid as a proxy for lignin. As an example for vitamins the sterol compound ergosterol 
is shown. Chlorophyll- $b$ is an example of the group of porphyrin fluorophores.

It is well known that the fluorescence properties of a fluorophore (i.e. spectral parameters and intensity) are highly depended on its molecular environment, particularly: $\mathrm{pH}$, fluorophore concentration and interaction with other compounds. All measurements in the present study were, therefore, performed under consistent, defined conditions. Pure compounds were utilized for solid state investigations. For samples in solution or suspension, defined $\mathrm{pH}$ and fluorophore concentrations were chosen to ensure comparability of the spectral parameters (see Sect. 3.2 for more details). The molecular environment within biological samples, such as cells and tissue, is much more dynamic and complex than in a defined test environment. As a result the position and intensity of fluorescence modes shown may differ from in situ measurements within actual biological samples. Bearing this complexity in mind, however, we suggest that the presented results can be seen as a general characterization and overview, providing a collection of fluorescence landmarks for different compounds relevant to atmospheric PBAP.

Under atmospheric conditions aerosols can contain wide ranges of moisture content, from extremely dry particles to nuclei suspended in cloud water droplets. Hydration state has also been found to significantly influence the fluorescence properties of a fluorophore (Lakowicz, 1999; Pöhlker et al., 2012). Accordingly, spectra for most materials in this study were each recorded in solid, solution, and suspension phases, respectively. All EEMs of solvated or suspended samples show clearly defined fluorescence modes with only weak interference by light scattering effects. In EEMs of solid state compounds fluorescence modes, by contrast, are usually less clearly resolved and exhibit stronger light scattering, broader fluorescence modes, and an elevated fluorescent background. This background effect is more pronounced in white samples with very weak fluorescence modes, and we propose that the light detected as fluorescence is simply a function of light leakage (i.e. the tails of the 1 st and 2 nd order elastic scattering peaks cause a significant enhancement in signal in the absence of true molecular fluorescence). For this reason, the absolute intensity of all powdered samples have been normalized, as discussed in Sect. 3.2. Moreover a shift in location of emission peaks from solid- and solution-phase samples (e.g. cellulose in Figs. 2m and S2k in the Supplement, riboflavin in Figs. 2f and S2f in the Supplement) was also observed.

Molecular fluorescence generally provides less characteristic spectra than other methods of spectroscopy, making detailed chemical analysis impossible in most cases. Mixing of emission peaks from different fluorophores has been particularly well described for bacteria (Marose et al., 1998). Different compounds also exhibit large variations in the intensity of fluorescent emission. Compounds such as pyridoxine and neopterin emit intensly even in low concentrations, for example, whereas fluorescent emission of phenylalanine and ferulic acid exhibited weak emission in all cases. The intensity of fluorophores frequently discussed within the bioaerosol detection community, such as tryptophan, NADPH and riboflavin, can be characterized among the compounds shown as having a medium level of fluorescent emission. However, fluorescence intensity is a complex function of various parameters such as concentration, extinction coefficient at $\lambda_{\text {ex }}$ and quantum yield at $\lambda_{\text {em }}$ as well as influences by the molecular environment. Accordingly, only semi-quantitative comparison of intensity levels is possible based on the presented results.

\subsection{Spectral mapping of biological fluorophores}

As a way of summarizing the properties of key biofluorophores, Fig. 3 highlights fluorescent emission peaks (and corresponding mode widths), but ignores differences in intensity among the compounds. Most compounds chosen exhibit peaks at relatively short $(<500 \mathrm{~nm})$ wavelengths of excitation and emission and appear in the lower left of Fig. 3 (i.e. $\lambda_{\mathrm{ex}}=250-400 \mathrm{~nm}, \lambda_{\mathrm{em}}=300-500 \mathrm{~nm}$ ). Riboflavin and chlorophyll- $b$, however, uniquely exhibit significantly larger $\Delta \lambda_{\text {Stokes }}$ (i.e. the right side of the plot). Furthermore, it is obvious that the modes of many fluorophores cluster in two "emission hotspots". Hotspot I $\left(\lambda_{\mathrm{ex}}=\sim 280 \mathrm{~nm} ; \lambda_{\mathrm{em}}=300\right.$ $530 \mathrm{~nm}$ ) is dominated by amino acids and proteins, biopolymers such as cellulose and chitin, and several coenzymes (i.e. pyridoxamine, riboflavin). Hotspot II $\left(\lambda_{\mathrm{ex}}=330\right.$ $360 \mathrm{~nm} ; \lambda_{\mathrm{em}}=390-460 \mathrm{~nm}$ ) shows emission from the majority of coenzymes (i.e. NADPH, pyridoxine, folic acid), the proxies for lignin (ferulic acid, phenylcoumarin) and DPA. Note that experimental data for DPA are not available through the present study, but were added to Fig. 3 from Sarasanandarajah et al. (2005) because of its importance in bacterial spores. Both emission hotspots directly correspond with the operational range of most bioaerosol detectors, as shown in Fig. 1. Excitation at $\sim 280$ and $\sim 360 \mathrm{~nm}$ are particularly important wavelengths to excite many atmospherically important biofluorophores. Beyond these established excitation bands, however, the development of relatively cheap diodes lasers for consumer electronic technology (e.g. Blu-Ray Disc ${ }^{\mathrm{TM}}, \lambda_{\mathrm{ex}}=405 \mathrm{~nm}$ ) within the last several years has opened up new possibilities for the design of FBAP detection instrumentation. Extensive laboratory studies have not yet been performed to validate the use of these new sources for FBAP detection and will be necessary before interpretation of complex aerosol samples will be meaningful. Figure 3 shows that the $405 \mathrm{~nm}$ excitation band is located in a spectral region where only relatively few biofluorophores (e.g. riboflavin, chlorophyll- $b$ and chitin) are efficiently excited (see also Fig. S6 in the Supplement). Riboflavin, however, is ubiquitous within PBAP and the relative selectivity of $\lambda_{\mathrm{ex}}=405 \mathrm{~nm}$ may eventually prove particularly successful at PBAP detection. 

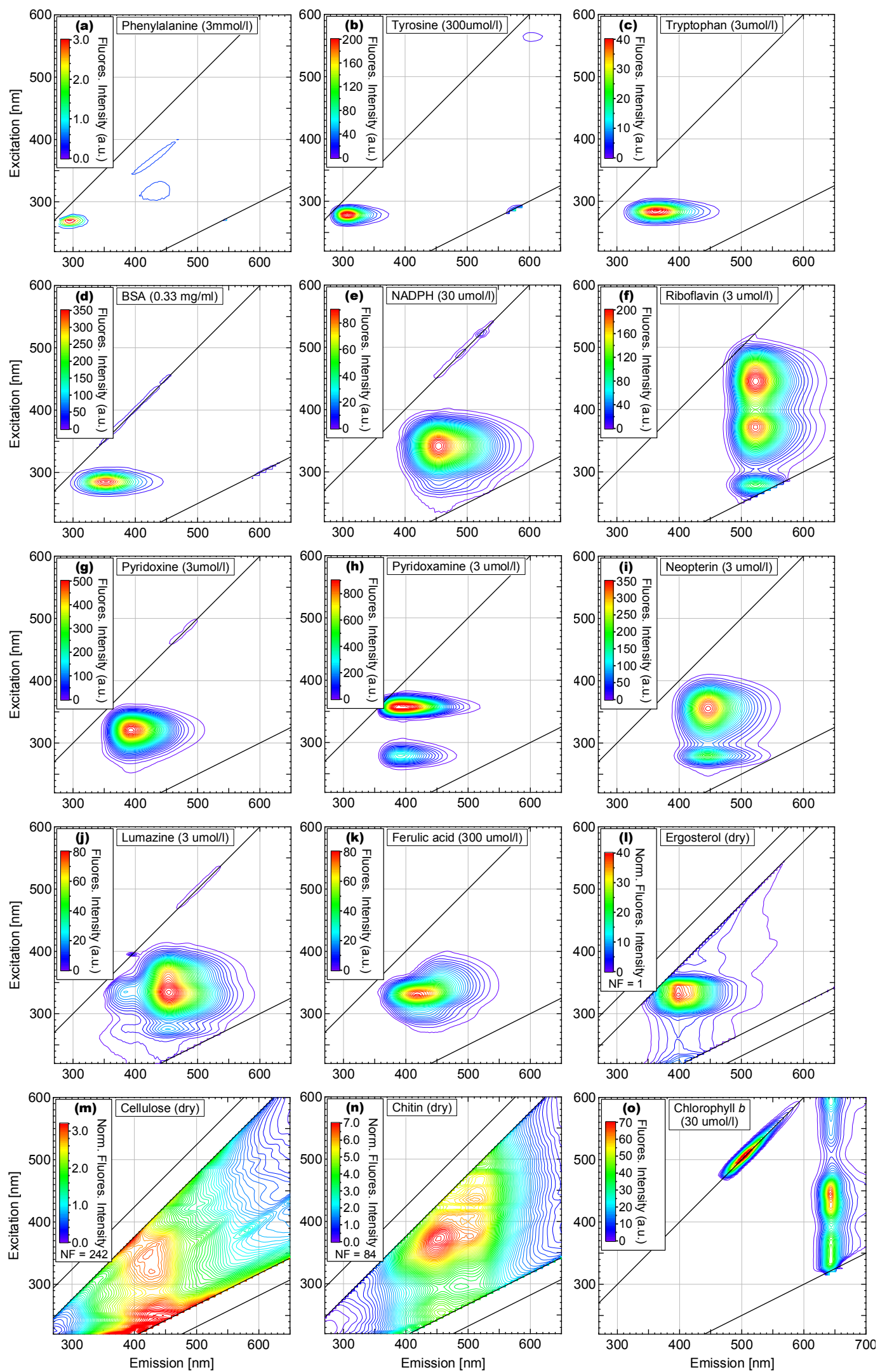

Fig. 2. EEM contour profiles for selected pure biological fluorophores in solid or solvated state. Intensity color scale has been adjusted to intensity of individual components. All EEMs are normalized as discussed in text (Sect. 3.2). Normalization factor (NF) is reported for each solid-state sample. Lower NF indicates higher fluorescence intensity. Note change in $\mathrm{x}$-axis scale for chlorophyll- $b$. 


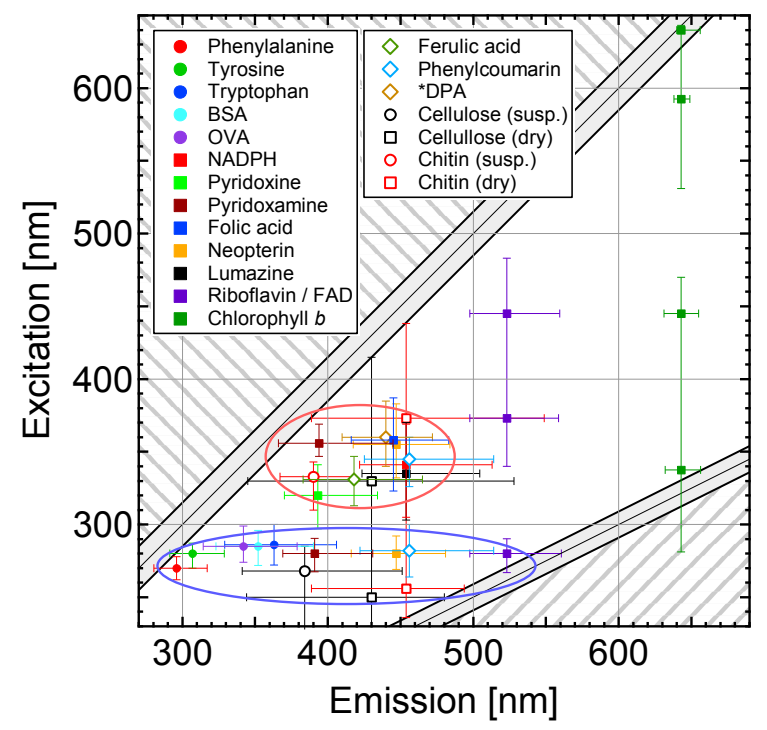

Fig. 3. Overview EEM mapping the spectral position of biological fluorophores. Protein fluorophores are represented by solid circular markers, coenzyme fluorophores by solid square markers and structural fluorophores by open markers. Full width half max (FWHM) of emission peaks is represented by horizontal and vertical bars. Differences in relative fluorescence intensity are neglected. For multimodal fluorophores all modes are shown. Data refer to measurements of solved fluorophores in PBS. For cellulose and chitin results of solid state and suspension state spectra are shown. * Data for DPA are taken from Sarasanandarajah et al. (2005).

Accordingly, a variety of fluorophores within atmospheric particles are potential targets for these instruments. It is clear that PBAPs comprise potentially many different fluorescent constituents at the same time (see Table 1). For example, bacteria have been shown to contain a mixture of fluorescent coenzymes such as pyridine, flavin, pyridoxine and pteridine compounds (Dalterio et al., 1987; Wlodarski et al., 2006). It can thus be assumed that ambient FBAP detection based on autofluorescence usually detects a mixed signal from potentially many different fluorophores. In contrast to technical applications where autofluorescence of NADH is directly used to monitor the metabolic status of yeast or bacteria in bioreactors (Marose et al., 1998; Johansson and Liden, 2006), the high diversity of organisms, debris and other compounds in the atmosphere makes a selective assignment of the measured fluorescence to a certain fluorophores difficult. This suggestion is not new, however, and several groups have investigated the use of varied post-detection techniques (e.g. principle component analysis) to elucidate further information from ambient PBAP (e.g. Pinnick et al., 2004; Pan et al., 2010, 2011). The only coenzyme which is largely free from interference by other biofluorophore is riboflavin and related flavoproteins (Koenig and Schneckenburger, 1994).

Figure 3 also shows that the fluorescence signal of the proteins sampled (BSA, OVA) is very similar to the tryptophan signal. Because the fluorescent emission of tyrosine and phenylalanine have a smaller $\Delta \lambda_{\text {Stokes }}$ than tryptophan this may suggest that these amino acids do not contribute significantly to the overall fluorescence signal in native proteins where they occur (BSA: 30 Phe residues, 21 Tyr, 3 Trp; Hirayama et al., 1990; OVA: 15 Phe, 10 Tyr, 3 Trp; Nisbet et al., 1981). In addition, it can be seen that the modes of BSA and OVA are slightly red-shifted with respect to tryptophan, which is due to the specific influence of the microenvironment of the folded protein (Lakowicz, 1999). The position of each individual fluorescence mode in Fig. 3 is determined by the structural nature of the corresponding fluorophore, such as the extent of $\pi$-bond conjugation or influence of electron donating or withdrawing groups. Aizawa et al. (2008) provides an overview EEM map showing the spectral position of PAHs depends on the size of their $\pi$-bond system. Figure 3 displays a similar map for biofluorophores presented here. Sampled compounds that contain small monocyclic fluorophore groups such as phenyl (phenylalanine), phenol (tyrosine) and indol (tryptophan) are excited by radiation in the UV and blue visible range $\left(\lambda_{\mathrm{ex}}=260-290 \mathrm{~nm} ; \lambda_{\mathrm{em}}=290\right.$ $370 \mathrm{~nm}$ ). Compounds with larger fluorophores such as pyridine (i.e. pyridoxine and dipicolinic acid), nicotinamide $(\mathrm{NAD}(\mathrm{P}) \mathrm{H})$ and pteridine (i.e. folic acid, lumazine) are spectrally more red-shifted $\left(\lambda_{\text {ex }}=280-370 \mathrm{~nm} ; \lambda_{\text {em }}=390\right.$ $470 \mathrm{~nm})$. Compounds containing large aromatic structures such as flavins and porphyrins (chlorophyll- $b$ ) are even further red-shifted $\left(\lambda_{\text {ex }}=280-640 \mathrm{~nm} ; \lambda_{\text {em }}=510-660 \mathrm{~nm}\right)$. In addition, increasing the size of the $\pi$-bond system opens more potential excitation pathways for electron transition, thus extending the fluorescence band over a much broader range of excitation wavelengths (i.e. for riboflavin and chlorophyll- $b$ ).

In addition to the investigation of fluorescence properties of pure fluorophores, the analysis of biological standard compounds (i.e. bacteria and pollen) promises to help to explain the selectivity of online FBAP detection. A full investigation of microorganism fluorescence is beyond the scope of this text, but Saccharomyces cerevisiae (baker's yeast) is shown in Fig. 4 as an example of an actively metabolizing organism and surrogate for atmospheric PBAP. The fluorescence properties of this organism are well described, due to its various industrial applications. According to Marose et al. (1998) tryptophan, $\mathrm{NAD}(\mathrm{P}) \mathrm{H}$, pyridoxine, pyridoxal 5'-phosphate and flavins are the dominating fluorophores in S. cerevisiae. The ratio of their relative emission intensities has been used to monitor the metabolic status of the cells and to estimate the overall biomass. The EEM in Fig. 4 shows a fluorescence pattern corresponding with several of the previously mentioned fluorophores. A strong peak at $285 / 350 \mathrm{~nm}\left(\lambda_{\mathrm{ex}} / \lambda_{\mathrm{em}}\right)$ is likely caused by proteins, particularly tryptophan residues, whereas the signal at $230 / 350 \mathrm{~nm}$ appears to be also protein fluorescence due to deep UV excitation (Bhartia et al., 2008). An emission signal occurs at $350 / 450 \mathrm{~nm}$ that is most probably $\mathrm{NAD}(\mathrm{P}) \mathrm{H}$, although pteridin coenzymes may also 


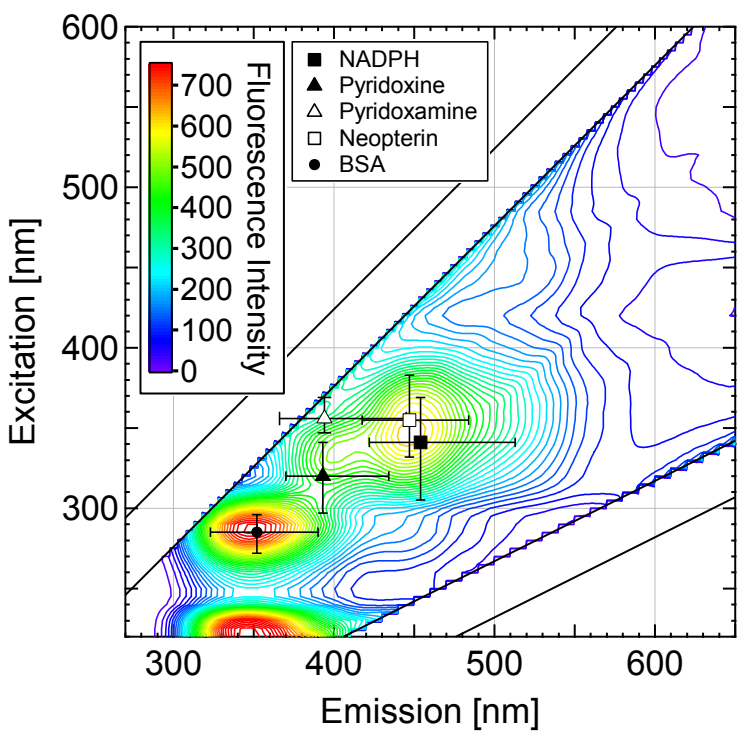

Fig. 4. EEM contour profile for Saccharomyces cerevisiae (baker's yeast). Spectral positions of selected pure fluorophores are shown for comparison. BSA is chosen as a general proxy for protein.

contribute to this signal (Michal, 1999; Kopczynski et al., 2005). A shoulder at $340 / 410 \mathrm{~nm}$ is likely caused by pyridoxine coenzymes. However, no flavin signal was observed. For purpose of illustration the spectral positions of the corresponding fluorophores (based on the measurements in Fig. 2) are projected into the EEM. In further studies EEMs will be used to characterize the fluorescence properties of various bioaerosol standard particles.

\subsection{EEMs of potential interferents}

In order to estimate the relative interfering potential of the compound types discussed in Sect. 2.7 fluorescence spectra of HULIS (humic and fulvic acid), PAHs (pyrene, naphthalene, phenanthrene, fluoranthene), mineral dust (kaolin and Arizona test dust) and soot (biomass burning and diesel soot) were investigated. Figure 5 shows EEMs of selected compounds, with additional samples shown in Fig. S3 in the Supplement, and can be grouped into two qualitatively distinct categories: (I) EEMs with clearly resolved fluorescence modes (e.g. all solutions and suspensions, dry PAHs) and (II) EEMs without clear modes, but with significant light emission over a wide spectral "plateau" (all dry samples with the exception of PAHs).

EEMs of HULIS surrogates which show defined fluorescence modes are consistent with results from DOM analysis. Humic and fulvic acids in solution exhibit broad modes $(390 / 490,450 / 520)$, but with relatively low intensity and resemble fluorescence behavior of DOM (e.g. Chen et al., 2003; Wedborg et al., 2007). In contrast, PAH compounds show strongly fluorescent emission, the peak location of which corresponds to the size of the $\pi$-bond system. In general, PAH samples in the solid state can be excited efficiently over a wide wavelength range (230-390 nm), whereas samples in solution show relatively narrow, defined excitations.

In contrast to compounds that show well defined modes of fluorescent emission, EEMs of dry powders such as mineral dust (kaolin and Arizona test dust) and HULIS (humic and fulvic acid) exhibit broad, featureless emission over an extended spectral area (230-500/350-600) with steep increase near the 1 st and 2 nd order scattering signals. We observed that the relative intensity level of this plateau correlates with the visible color of the samples. For example, the broad emission intensity of kaolin (white, Fig. S5h in the Supplement) is higher than that of fulvic acid (yellow, Fig. S5b in the Supplement), which is higher still than that of humic acid (brown, Fig. S5a in the Supplement). We further tested additional white powder compounds (i.e. $\mathrm{NaCl}$ and glass microspheres) not expected to show any classical fluorescent emission in this range. These also exhibit EEMs that are qualitatively almost identical with the other dry powder samples, with intensity levels similar to that of the white kaolin powder. This suggests that the featureless emission observed from these powder samples is spurious and does not originate as molecular fluorescence. We thus suggest that the "plateau" effect is a result of light leakage due to imperfect monochromators within the spectrofluorometer and that light arriving at the detector at wavelengths in between the dominant scattering lines largely represents the transmission tails of the elastic scattering signals. The presence of this elevated fluorescence background is minimal for compounds that exhibit defined fluorescence modes, is magnified in powdered samples with high surface area for reflection, and is highest in samples whose color reduces light absorption. In order to qualitatively eliminate these effects from EEMs of dry materials the spectra have been normalized as described in Sect. 3.2. Normalized spectra are shown in Figs. 5 and S3 in the Supplement, while a selection of raw EEMs can be found in Figs. S4 and S5 in the Supplement. According to De Souza Sierra et al. (1994) it is critical to correct fluorescence spectra of solid particulate matter for stray light transmitted by the excitation monochromator and scattered by the sample to ensure comparability. These normalized spectra offer the ability to semi-quantitatively compare fluorescent intensities from different materials. While quantitative comparisons within the list of dry materials or within the list of wet materials (solution, suspension) is possible, differences in normalization procedure between the two is quantitatively challenging by this technique.

\subsection{Comparison of autofluorescence from biofluorophores and interfering species}

Figure 6 shows a summary of selected biological and nonbiological compounds, excited at one of two wavelengths: either $280 \mathrm{~nm}$ (Fig. 6a and c) or $355 \mathrm{~nm}$ (Fig. 6b and d). These 

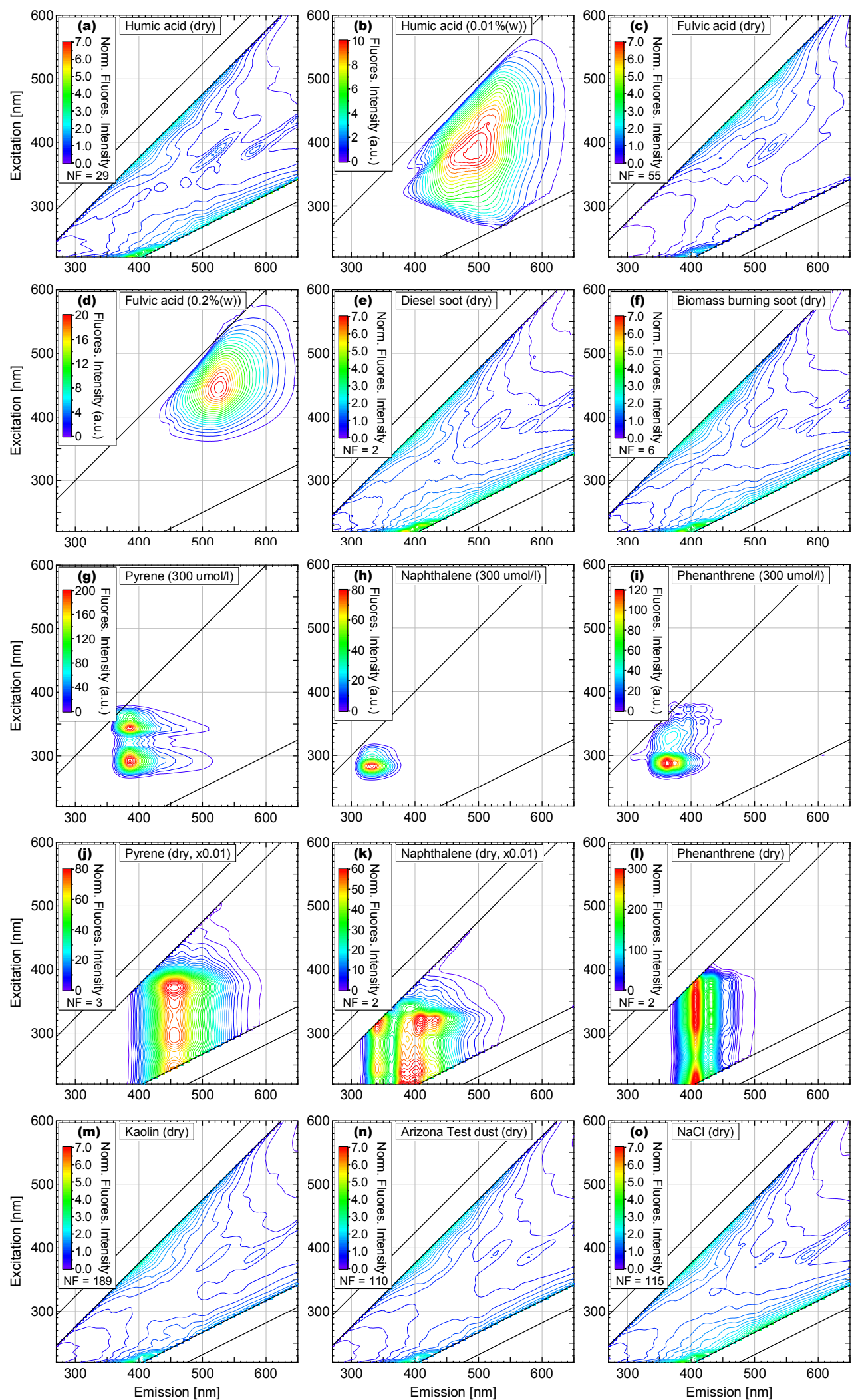

Fig. 5. Normalized EEM contour profiles for selected interferences in solid state and/or solution. Intensity color scale has been adjusted to intensity of individual components. All EEMs are normalized as discussed in text (Sect. 3.2). Normalization factor (NF) is reported for each solid-state sample. Lower NF indicates higher fluorescence intensity. 

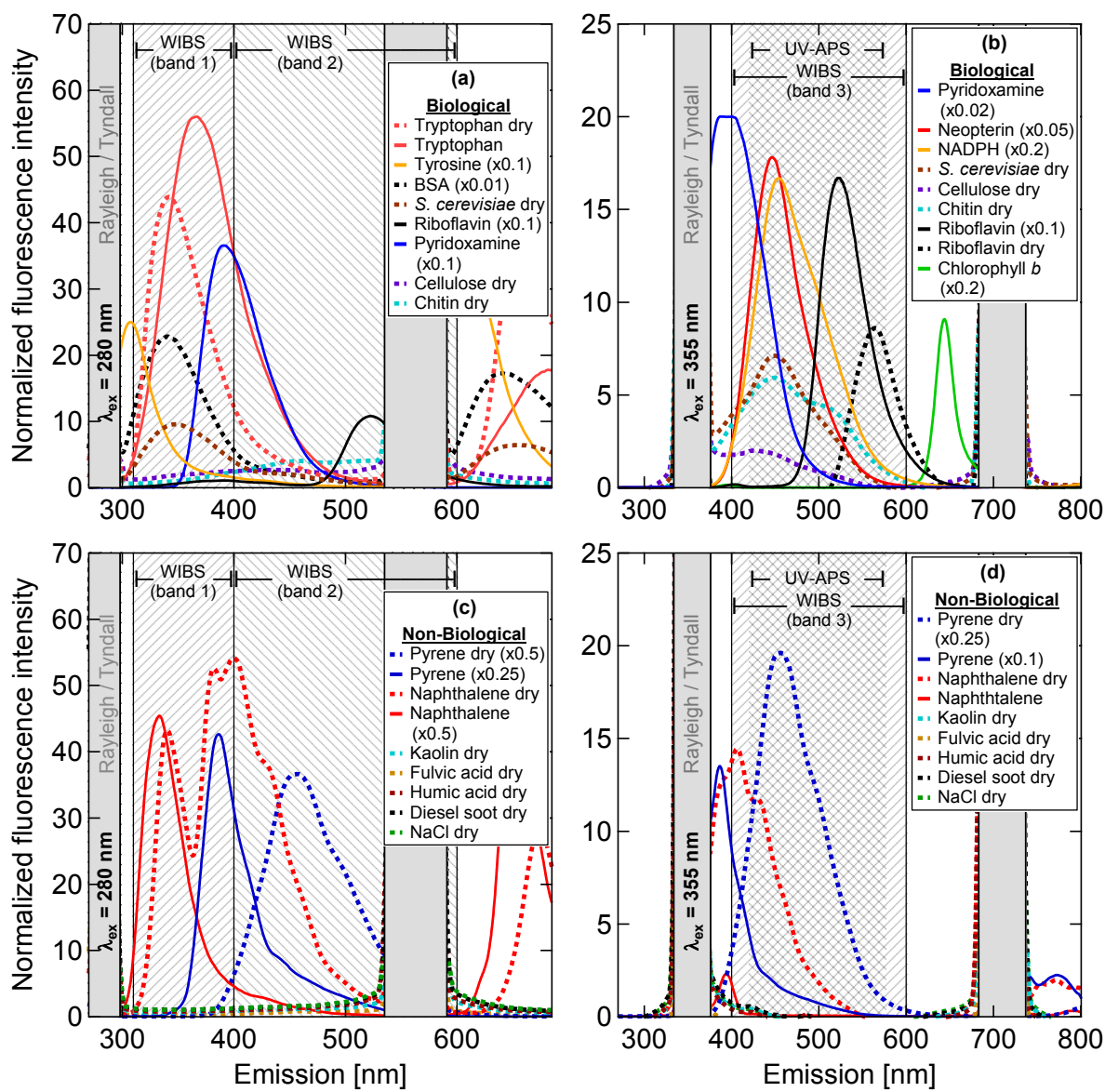

Fig. 6. Normalized fluorescence emission spectra of biofluorophores and potential interferences for selected excitation wavelengths $\lambda$ ex; (a) emission spectra of biological fluorophores at $\lambda_{\mathrm{ex}}=280 \mathrm{~nm}$; (b) emission spectra of biological fluorophores at $\lambda_{\mathrm{ex}}=355 \mathrm{~nm}$; (c) emission spectra of potential interferences at $\lambda_{\mathrm{ex}}=280 \mathrm{~nm}$; (d) emission spectra of potential interferences at $\lambda_{\mathrm{ex}}=355 \mathrm{~nm}$. Dashed lines indicate samples in dry state, solid lines indicate samples in solution. Spectra were scaled in some cases to fit on same y-axis. For example, pyridoxamine in (a) peaks at $\sim 350$ a.u., and not $\sim 35$ a.u. as shown.

wavelengths of excitation were chosen to highlight observed fluorescent emission within the two primary bands of fluorophores discussed in Sects. 4.1-4.2 and because they represent or approximate the excitation sources of two commercially available FBAP-detection instruments (UV-APS and WIBS). Detected emission ranges for both instruments are shown by shaded regions on the plot, although it is important to note that the second WIBS excitation source produces radiation at $370 \mathrm{~nm}$ and not at $355 \mathrm{~nm}$ (corresponding to UV-APS) as shown in Fig. $6 \mathrm{~b}$ and d. Colored traces show individual fluorophores selected to represent key molecules for FBAP detection from Table 1. This set of summary plots enables a semi-quantitative comparison of fluorophore importance, in particular regarding the influence of potential interferences. Fluorescence properties of certain biofluorophores have been investigated in various studies, however, much less information is available regarding the intercomparison between very different compound types (in particular biofluorophores and non-biological fluorophores). Figure 6 provides a simple approach to fill this gap.
In the raw (non-normalized) spectra (Figs. S4, 5 in the Supplement) the "plateau-like" emission of materials such as fulvic acid, kaolin, $\mathrm{NaCl}$, and cellulose can be easily seen, while the normalized spectra of such materials (Fig. 6) show only weak fluorescence. The normalized spectra of $\mathrm{NaCl}$ can be used as a surrogate post-normalization background, because it is not expected to fluorescence at wavelengths used here and because it exhibits the most fluorescence intensity of the "non-fluorescent" powders. As such, the emission spectrum for $\mathrm{NaCl}$ retains a measureable background when excited at $280 \mathrm{~nm}$, increasing from a minimum $I \sim 1.0$ at $\lambda_{\mathrm{em}, 350}$ to $\sim 2.0$ at $\lambda_{\mathrm{em}, 550}$, while it exhibits a steep valley profile when excited by $355 \mathrm{~nm}$ radiation, but with $I<0.5$ for all emission between 400 and $650 \mathrm{~nm}$. Small peaks in emission spectra of weakly fluorescing compounds can consistently be seen at $\sim 340,422,459$, and $485 \mathrm{~nm}$ for $\lambda_{\text {ex, } 280}$ and at 420 and $485 \mathrm{~nm}$ for $\lambda_{\mathrm{ex}, 355}$. The most prominent of these appear as subtle diagonal lines between the 1st and 2nd order elastic scattering lines on EEMs of weakly fluorescing dry powders (e.g. Figs. $2 \mathrm{~m}$ and $5 \mathrm{a}, \mathrm{c}, \mathrm{m}-\mathrm{o}$ ). These 
do not appear for fluorescent compounds, however, and are assumed to be a product of weakly interfering elastic scattering processes. In contrast to weakly fluorescing molecules, emission by biofluorophores and PAH compounds show clearly resolved peaks before and after normalization, and we roughly categorize these to be fluorescent in all cases. In general it can be stated that position and linewidth of fluorescence emission peaks in EEMs are independent of $\lambda_{\text {ex }}$ due to radiative electron relaxation from the lowest vibrational level of the first excited electronic state (Sect. 1.2). Thus, fluorescence signals are indicated by vertical lines or individual peaks in EEMs as presented here. Further, the only parameter that varies along the excitation axis (vertical) is the fluorescence intensity, which does so as a function of the absorption spectrum of the fluorophore. In contrast, signals of other light scattering effects (i.e. Rayleigh, Tyndall and Raman) are a function of $\lambda_{\text {ex }}$ and accordingly can be seen as diagonal lines within the EEMs (Coble et al., 1990).

Figure $6 \mathrm{a}$ and $\mathrm{b}$ highlight the fact that a wide variety of molecules associated with biological organisms fluoresce. Moreover the compounds shown in Fig. 6, which were chosen to represent larger groups of molecules from Table 1, underline the previously mentioned suggestion that a large variety of fluorophores contribute to the overall fluorescence signal detected by online FBAP instrumentation. Among the nine biomolecules chosen, fluorescence is generally high. The only exceptions to this are cellulose and chitin. Cellulose shows essentially no fluorescence (similar emission profile of $\mathrm{NaCl})$ at $\lambda_{\mathrm{ex}, 280}$, but weak fluorescence at $\lambda_{\mathrm{ex}, 355}(I \sim 1$ at $\left.\lambda_{\text {em }}, 426\right)$. Chitin shows only marginally increased fluorescence for $\lambda_{\text {ex }, 280}$ compared to cellulose, but significant emission for $\lambda_{\mathrm{ex}, 355}\left(I \sim 5.9\right.$ at $\lambda_{\mathrm{em}, 426}$ and $\sim 4.2$ at $\left.\lambda_{\mathrm{em}, 515}\right)$. All other samples of biological fluorophores and material chosen exhibit relatively high intensity peaks in each emission spectrum shown in Fig. 6. Amino acid peaks, especially tryptophan, showed fluorescent emission among the most intense of compounds sampled. Samples of isolated protein and of the $S$. cerevisae each showed similar peak placement with tryptophan indicating that tryptophan is the major and crucial fluorophore in proteins.

In contrast, most of the seven non-biological samples shown in Fig. 6c and d show very weak fluorescence. Pyrene and naphthalene, shown here as examples of PAH fluorescence, are the only exceptions to this trend and show sharp peaks in the range of $333-456 \mathrm{~nm}$ in the emission spectra for both excitation wavelengths, where $I: 54-172$ for $\lambda_{\text {ex }, 280}$ and 2-140 for $\lambda_{\text {ex,355. Strong fluorescent emission of }}$ pyrene is observed for $\lambda_{\mathrm{ex}, 280}$ and $\lambda_{\mathrm{ex}, 355}$ whereas naphthalene shows only fluorescence when excited at $280 \mathrm{~nm}$. Moreover, large differences in $\lambda_{\text {em }}$ can be observed between solid state and solution samples, for example pyrene in $n$-hexane exhibits $\lambda_{\mathrm{em}, 280}=387 \mathrm{~nm}$, while in the solid state exhibits $\lambda_{\text {em }, 280}=457 \mathrm{~nm}$. As mentioned, $\mathrm{NaCl}$ is expected to exhibit no emission of classically-termed fluorescence, but four of the other compounds chosen show fluorescent emission levels at or below the level of $\mathrm{NaCl}$ for each excitation wavelength chosen in Fig. 6. This indicates that, while mineral dust has been shown to fluoresce in some circumstances, kaolin fluorescence is insignificantly weak compared with the intensity of the biofluorophores measured here. Fulvic and humic acids analyzed in this study also exhibited very weak fluorescence. This could indicate that HULIS may not cause significant interference within FBAP measurements because of a comparatively low level of fluorescent intensity compared to biological material. However, these effects are complicated and contain a high degree of uncertainty (see Sect. 2.7). In particular, fluorescence from single particles may exhibit different trends from that of the bulk. While pure PAH compounds were observed to fluoresce intensely, diesel and biomass burning soot that likely contain PAH molecules both show emission levels below the surrogate $\mathrm{NaCl}$ background. While still a preliminary determination, the spectra of these soot samples corroborate suggestions by Lewitzka and Niessner (1995) and Panne et al. (2000) that soot exhibits only weak fluorescence due to inner quenching effects.

For excitation at $355 \mathrm{~nm}$ fluorophores such as $\mathrm{NAD}(\mathrm{P}) \mathrm{H}$, pyridoxamine, neopterin, riboflavin, chitin and cellulose likely contribute to wavelength-integrated fluorescence detection by UV-APS ( $\left.\lambda_{\mathrm{em}}=420-575 \mathrm{~nm}\right)$ and WIBS $\left(\lambda_{\mathrm{em}}=400-600 \mathrm{~nm}\right)$ instruments, but this depends largely on exact instrumental optics and operational emission thresholds. Moreover a large number of other molecules (i.e. secondary metabolites) emit in the same spectral region, as discussed in Sect. 2. Accordingly we suggest that within this spectral range an integrated fluorescence signal provides no clear selectivity for certain coenzymes (e.g. NAD(P)H) as indicators for viability, and users of such instrumentation should avoid the assumption that these molecules dominate the fluorescence signal in all cases. Neither UV-APS nor WIBS instrument is likely to detect chlorophyll, because of its large $\Delta \lambda_{\text {Stokes. }}$ The WIBS channels measuring emission after $\lambda_{\text {ex,280 }}$ may be more sensitive to influence from PAHs when the molecular environment in the sampled atmospheric particle approximates that of the solutionphase PAHs presented here. However, for excitation at $280 \mathrm{~nm}$, the region exemplified by the first WIBS emission band $\left(\lambda_{\mathrm{em}}=310-400 \mathrm{~nm}\right)$ suggests that fluorophores such as proteins and particularly tryptophan-containing proteins will dominate the emission signal in most cases, with some coenzymes (i.e. pyridoxamine, riboflavin) also important. The region exemplified by the second WIBS emission band $\left(\lambda_{\mathrm{em}}=400-600 \mathrm{~nm}\right)$ at $\lambda_{\mathrm{ex}, 280}$ will also likely detect protein and coenzyme fluorescence, however, to a lower extent.

The emission spectrum observed for $S$. cerevisiae suggests by extrapolation that viable PBAP can, not surprisingly, be expected to exhibit clear signals in both FBAP instruments. Given the fluorescence spectra shown, however, the WIBS may be more likely to see higher intensity for this organism in the first of two channels at $\lambda_{\mathrm{ex}, 280}$. 


\section{Conclusions and outlook}

In this study a systematic literature survey of key biological fluorophores which are relevant for atmospheric science is presented. The individual compounds are organized into major fluorophore classes and characterized by their biological role and abundance as well as by certain fluorescence properties. As a first approach the relative atmospheric importance of individual fluorophores or classes of fluorophores have been estimated. In addition, emission spectra have been measured as a function of excitation wavelength for various representative compounds. An overview of individual fluorophores shows that unique autofluorescence properties can indeed be useful for discrimination of biological material by online FBAP methods. Moreover key biological fluorophores can be collected into two relatively narrow excitation bands ( $\sim 280$ and $\sim 360 \mathrm{~nm})$. Each of these bands has been utilized by designers of FBAP instruments for bioaerosol detection.

Amino acids and proteins are among the most important fluorophores at $\lambda_{\mathrm{ex}, 280}$, while some coenzymes (e.g. pyridoxamine, riboflavin) are also potentially important. Coenzymes such as $\mathrm{NAD}(\mathrm{P}) \mathrm{H}$, pyridoxine compounds and pteridines are among the most highly fluorescent compounds at $\lambda_{\mathrm{ex}, 355}$, but structural biopolymers (e.g. chitin, lignin) are also important. The complexity of overlapping spectra for fluorophores expected to be present in many classes of PBAP highlights the difficulty in making molecular determination of fluorescence origin from spectrally integrated signals detected in broad emission bands. Care should be taken, therefore, not to assume molecular identity from signals from instruments such as the UV-APS and WIBS. Further, the ability to determine cell viability for an unknown biological particle arriving at a detector may be difficult by single wavelength fluorescence alone, as has been suggested in depth previously (e.g. Pinnick et al., 2004). More work investigating standard particles in the laboratory are needed before uncertainties in these suggestions can be reduced, however.

A collection of atmospherically relevant non-biological compounds have also been analyzed and presented here. These data suggest that some non-biological materials could potentially contribute to fluorescence at wavelengths used by FBAP detectors (e.g. PAHs and SOA), whereas the majority of compounds suggested to cause interference (e.g. HULIS, mineral dust, soot) are less likely to contribute signal due to extremely weak intensity. SOA were not investigated here, because experimental procedures for producing oxidized aerosol in environmental chambers are beyond the scope of this text. Lab-generated SOA have been shown to fluoresce under certain conditions (Bones et al., 2010), though this has not been documented systematically within scientific literature. While SOA can dominate submicron particle concentrations, its contribution to supermicron particle mass is probably small. As such, its influence on the fluorescence signal of supermicron FBAP is likely also very

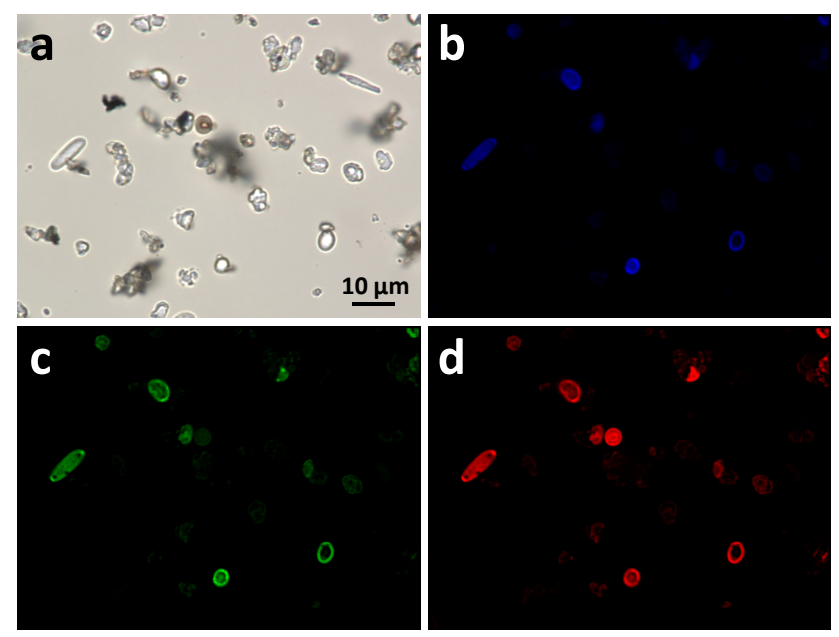

Fig. 7. Microscopy pictures of ambient aerosol sample. Illumination source: (a) brightfield, (b) $\lambda_{\mathrm{ex}}=340-380 \mathrm{~nm}, \lambda_{\mathrm{em}}=435$ 485 , (c) $\lambda_{\text {ex }}=465-495 \mathrm{~nm}, \lambda_{\mathrm{em}}=510-560$, (d) $\lambda_{\mathrm{ex}}=540-580 \mathrm{~nm}$, $\lambda_{\mathrm{em}}=600-660$.

small, although this should be investigated further. PAHs, which often are intensely fluorescent, are largely present in atmospheric aerosols on the surface of soot particles, but the complex chemical environments of soot have been shown to largely quench fluorescence. As a result of this and the fact that soot also often peaks at submicron sizes PAHs are considered to contribute only minimally to FBAP number, though they could cause potential interference in some cases. Despite uncertainties based on this bottom-up approach of addressing fluorescent properties of selected compounds the results of this laboratory study suggest that fluorescent properties of ambient FBAP are likely to be dominated by biological material in most cases. However, the authors are aware of the fact that the results presented in this study can only serve as a first general approach to aspects of selectivity in FBAP detection. In particular, further investigation must address differences between bulk and single particle fluorescence (Hill et al., 2009), the characteristic fluorescence fingerprints of authentic bioparticles and the impact of different atmospheric conditions and aging.

As a proof of concept study we collected ambient aerosol in Mainz, Germany and other locations for investigation of autofluorescence via fluorescence microscopy. Initial observations show that particles that fluoresce most strongly also exhibit characteristic biological morphologies, based on visual evidence presented here (Fig. 7). These ambient studies need to be furthered in much greater detail, but again provide a similar conclusion as given by the laboratory fluorescence study presented here that ambient FBAP appear to be comprised at least heavily of particles from biological origin, consistent with previous observations reported by Pöschl et al. (2010) and Huffman et al. (2012). Further work is necessary and forthcoming in order to fill in important gaps in 
understanding. For example, the fluorescence properties of standard microorganism types have been investigated in the laboratory under varying environmental conditions and will be presented in a follow-up study.

\section{List of frequently used acronyms.}

\begin{tabular}{|c|c|}
\hline Acronym & Description \\
\hline AA & amino acid \\
\hline AFS & aerosol fluorescence sensor \\
\hline AGE & advanced glycation end-product \\
\hline $\mathrm{APF}$ & age pigment-like fluorophore \\
\hline $\mathrm{BP}$ & band-pass \\
\hline BSA & bovine serum albumin \\
\hline BWA & biological warfare agent \\
\hline $\mathrm{CCN}$ & cloud condensation nuclei \\
\hline DAPI & 4',6-diamidino-2-phenylindole \\
\hline DNA & deoxyribonucleic acid \\
\hline DOM & dissolved organic matter \\
\hline DPA/CaDPA & $\begin{array}{l}\text { dipicolinic acid/calcium dipicolinic } \\
\text { acid }\end{array}$ \\
\hline EEM & excitation-emission matrix \\
\hline FAD & flavin adenine dinucleotide \\
\hline FBAP & fluorescent biological aerosol particles \\
\hline FISH & fluorescence in-situ hybridization \\
\hline FMN & flavin mononucleotide \\
\hline FWHM & full width half max \\
\hline GFP & green fluorescent protein \\
\hline HULIS & humic-like substances \\
\hline IN & ice nuclei \\
\hline LIF & light/laser-induced fluorescence \\
\hline MAA & mycosporin-like amino acid \\
\hline MS & mass spectrometry \\
\hline $\mathrm{NADH}$ & nicotinamide adenine dinucleotide \\
\hline NADPH & $\begin{array}{l}\text { nicotinamide adenine dinucleotide } \\
\text { phosphate }\end{array}$ \\
\hline $\mathrm{NAD}(\mathrm{P}) \mathrm{H}$ & NADH and NADPH \\
\hline Nd:YAG & $\begin{array}{l}\text { neodymium-doped yttrium aluminium } \\
\text { garnet }\end{array}$ \\
\hline NF & normalization factor \\
\hline OVA & ovalbumin \\
\hline PAH & polycyclic aromatic hydrocarbons \\
\hline PBAP & primary biological aerosol particles \\
\hline PBS & phosphate-buffered saline \\
\hline PCR/qPCR & $\begin{array}{l}\text { polymerase chain reaction/quantitative } \\
\text { polymerase chain reaction }\end{array}$ \\
\hline Phe & phenylalanine \\
\hline PM & particulate matter \\
\hline PMT & photomultiplier tube \\
\hline RET & resonance energy transfer \\
\hline RNA & ribonucleic acid \\
\hline SOA & secondary organic aerosols \\
\hline $\operatorname{Trp}$ & tryptophan \\
\hline Tyr & tyrosine \\
\hline
\end{tabular}

$\begin{array}{ll}\text { UV } & \text { ultraviolet } \\ \text { UV-APS } & \text { ultraviolet aerodynamic particle sizer } \\ \text { VBNC } & \text { viable but non-culturable } \\ \text { VOC } & \text { volatile organic compound } \\ \text { WIBS } & \text { wide issue bioaerosol sensor }\end{array}$

\section{Supplementary material related to this article is available online at: http://www.atmos-meas-tech.net/5/37/2012/ amt-5-37-2012-supplement.pdf.}

\begin{abstract}
Acknowledgements. This work has been funded by the Max Planck Society, the Max Planck Graduate Center and the LEC Geocycles Mainz. The authors gratefully acknowledge support by M. O. Andreae, J. Schneider, K. Selzle and W. Elbert and helpful conversation with D. R. Huffman, M. Shiraiwa, H. Su and M. Ermel.
\end{abstract}

The service charges for this open access publication have been covered by the Max Planck Society.

Edited by: J. Curtius

\section{References}

Agranovski, V., Ristovski, Z., Hargreaves, M., Blackall, P. J., and Morawska, L.: Performance evaluation of the UVAPS: influence of physiological age of airborne bacteria and bacterial stress, J. Aerosol Sci., 34, 1711-1727, doi:10.1016/s00218502(03)00191-5, 2003.

Aizawa, T. and Kosaka, H.: Investigation of early soot formation process in a diesel spray flame via excitation-emission matrix using a multi-wavelength laser source, Int. J. Eng. Res., 9, 7996, doi:10.1243/14680874jer01407, 2008

Aizawa, T. and Kosaka, H.: Effects of Fischer-Tropsch diesel fuel on soot formation processes in a diesel spray flame, Int. J. Eng. Res., 11, 79-87, doi:10.1243/14680874jer04709, 2010.

Albani, J. R., Sillen, A., Engelborghs, Y., and Gervais, M.: Dynamics of flavin in flavocytochrome $b(2)$ : A fluorescence study, Photochem. Photobiol., 69, 22-26, 1999.

Albinsson, B., Li, S. M., Lundquist, K., and Stomberg, R.: The origin of lignin fluorescence, J. Mol. Struct., 508, 19-27, 1999.

Alimova, A., Katz, A., Savage, H. E., Shah, M., Minko, G., Will, D. V., Rosen, R. B., McCormick, S. A., and Alfano, R. R.: Native fluorescence and excitation spectroscopic changes in Bacillus subtilis and Staphylococcus aureus bacteria subjected to conditions of starvation, Appl. Optics, 42, 4080-4087, 2003.

Amann, R. I., Ludwig, W., and Schleifer, K. H.: Phylogenetic identification and in-situ detection of individual microbial-cells without cultivation, Microbiol. Rev., 59, 143-169, 1995.

Ammor, M. S.: Recent advances in the use of intrinsic fluorescence for bacterial identification and characterization, J. Fluoresc., 17, 455-459, doi:10.1007/s10895-007-0180-6, 2007.

Ammor, S., Yaakoubi, K., Chevallier, I., and Dufour, E.: Identification by fluorescence spectroscopy of lactic acid bacteria isolated from a small-scale facility producing traditional dry sausages, J. Microbiol. Meth., 59, 271-281, doi:10.1016/j.mimet.2004.07.014, 2004. 
Andersson, H., Baechi, T., Hoechl, M., and Richter, C.: Autofluorescence of living cells, J. Microsc.-Oxford, 191, 1-7, 1998.

Andersson Engels, S., af Klinteberg, C., Svanberg, K., and Svanberg, S.: In vivo fluorescence imaging for tissue diagnostics, Phys. Med. Biol., 42, 815-824, 1997.

Andreae, M. O. and Crutzen, P. J.: Atmospheric aerosols: Biogeochemical sources and role in atmospheric chemistry, Science, 276, 1052-1058, 1997.

Andreae, M. O. and Gelencsér, A.: Black carbon or brown carbon? The nature of light-absorbing carbonaceous aerosols, Atmos. Chem. Phys., 6, 3131-3148, doi:10.5194/acp-6-3131-2006, 2006.

Andreae, M. O. and Rosenfeld, D.: Aerosol-cloudprecipitation interactions, Part 1 , The nature and sources of cloud-active aerosols, Earth-Sci. Rev., 89, 13-41, doi:10.1016/j.earscirev.2008.03.001, 2008.

Avidor, Y., Doherty, M. D., Olson, J. M., and Kaplan, N. O.: Fluorescence of pyridine nucleotides in mitochondria, J. Biol. Chem., 237, 2377-2383, 1962.

Bauer, H., Schueller, E., Weinke, G., Berger, A., Hitzenberger, R., Marr, I. L., and Puxbaum, H.: Significant contributions of fungal spores to the organic carbon and to the aerosol mass balance of the urban atmospheric aerosol, Atmos. Environ., 42, 5542-5549, doi:10.1016/j.atmosenv.2008.03.019, 2008.

Benson, R. C., Meyer, R. A., Zaruba, M. E., and McKhann, G. M.: Cellular autofluorescence - is it due to flavins, J. Histochem. Cytochem., 27, 44-48, 1979.

Bhartia, R., Hug, W. F., Salas, E. C., Reid, R. D., Sijapati, K. K., Tsapin, A., Abbey, W., Nealson, K. H., Lane, A. L., and Conrad, P. G.: Classification of Organic and Biological Materials with Deep Ultraviolet Excitation, Appl. Spectrosc., 62, 1070-1077, 2008.

Bigio, I. J. and Mourant, J. R.: Ultraviolet and visible spectroscopies for tissue diagnostics: Fluorescence spectroscopy and elastic-scattering spectroscopy, Phys. Med. Biol., 42, 803-814, 1997.

Billinton, N. and Knight, A. W.: Seeing the wood through the trees: A review of techniques for distinguishing green fluorescent protein from endogenous autofluorescence, Anal. Biochem., 291, 175-197, 2001.

Birdwell, J. E. and Valsaraj, K. T.: Characterization of dissolved organic matter in fogwater by excitation-emission matrix fluorescence spectroscopy, Atmos. Environ., 44, 3246-3253, doi:10.1016/j.atmosenv.2010.05.055, 2010.

Boerjan, W., Ralph, J., and Baucher, M.: Lignin biosynthesis, Annu. Rev. Plant Biol., 54, 519-546, doi:10.1146/annurev.arplant.54.031902.134938, 2003.

Bones, D. L., Henricksen, D. K., Mang, S. A., Gonsior, M., Bateman, A. P., Nguyen, T. B., Cooper, W. J., and Nizkorodov, S. A.: Appearance of strong absorbers and fluorophores in limoneneO-3 secondary organic aerosol due to NH4+-mediated chemical aging over long time scales, J. Geophys. Res.-Atmos., 115, D05203, doi:10.1029/2009jd012864, 2010.

Bonfantefasolo, P., Faccio, A., Perotto, S., and Schubert, A.: Correlation between chitin distribution and cell-wall morphology in the mycorrhizal fungus glomus-versiforme, Mycol. Res., 94, $157-165,1990$.
Bowers, R. M., Lauber, C. L., Wiedinmyer, C., Hamady, M., Hallar, A. G., Fall, R., Knight, R., and Fierer, N.: Characterization of Airborne Microbial Communities at a High-Elevation Site and Their Potential To Act as Atmospheric Ice Nuclei, Appl. Environ. Microbiol., 75, 5121-5130, doi:10.1128/aem.00447-09, 2009.

Bowers, R. M., McLetchie, S., Knight, R., and Fierer, N.: Spatial variability in airborne bacterial communities across land-use types and their relationship to the bacterial communities of potential source environments, ISME J., 5, 601-612, 2011.

Bozlee, B. J., Misra, A. K., Sharma, S. K., and Ingram, M.: Remote Raman and fluorescence studies of mineral samples, Spectroc. Acta Pt. A-Molec. Biomolec. Spectr., 61, 2342-2348, doi:10.1016/j.saa.2005.02.033, 2005.

Bridges, J. W., Davies, D. S., and Williams, R. T.: Fluorescence studies on some hydropyridines including compounds of vitamin B6 group, Biochem. J., 98, 451-468, 1966.

Bronk, B. V., Shoaibi, A., Nudelman, R., and Akinyemi, A.: Physical perturbation for fluorescent characterization of microorganism particles, in: Chemical and Biological Sensing, edited by: Gardner, P. J., Proceedings of the Society of Photo-Optical Instrumentation Engineers - Spie, Spie-Int Soc Optical Engineering, Bellingham, 169-180, 2000.

Brooks, J. and Shaw, G.: Sporopollenin a review of its chemistry paleochemistry and geochemistry, Grana, 17, 91-98, 1978.

Brosseau, L. M., Vesley, D., Rice, N., Goodell, K., Nellis, M., and Hairston, P.: Differences in detected fluorescence among several bacterial species measured with a direct-reading particle sizer and fluorescence detector, Aerosol Sci. Tech., 32, 545-558, 2000.

Brown, J. K. M. and Hovmoller, M. S.: Epidemiology - Aerial dispersal of pathogens on the global and continental scales and its impact on plant disease, Science, 297, 537-541, 2002.

Bueno, C. and Encinas, M. V.: Photophysical and photochemical studies of pyridoxamine, Helv. Chim. Acta, 86, 3363-3375, 2003.

Bundke, U., Reimann, B., Nillius, B., Jaenicke, R., and Bingemer, H.: Development of a Bioaerosol single particle detector (BIO IN) for the Fast Ice Nucleus CHamber FINCH, Atmos. Meas. Tech., 3, 263-271, doi:10.5194/amt-3-263-2010, 2010.

Burrows, S. M., Butler, T., Jöckel, P., Tost, H., Kerkweg, A., Pöschl, U., and Lawrence, M. G.: Bacteria in the global atmosphere - Part 2: Modeling of emissions and transport between different ecosystems, Atmos. Chem. Phys., 9, 9281-9297, doi:10.5194/acp-9-9281-2009, 2009.

Burshtein, N., Lang-Yona, N., and Rudich, Y.: Ergosterol, arabitol and mannitol as tracers for biogenic aerosols in the eastern Mediterranean, Atmos. Chem. Phys., 11, 829-839, doi:10.5194/acp-11-829-2011, 2011.

Campbell, S. D., Tremblay, D. P., Daver, F., and Cousins, D.: Wavelength comparison study for bioaerosol detection, in: Sensors, and Command, Control, Communications, and Intelligence, edited by: Carapezza, E. M., Proceedings of the Society of Photo-Optical Instrumentation Engineers - Spie, Spie-Int Soc Optical Engineering, Bellingham, 130-138, 2005.

Cannon, R. E. and Anderson, S. M.: Biogenisis of bacterial cellulose, Crit. Rev. Microbiol., 17, 435-447, 1991.

Castellan, A., Ruggiero, R., Frollini, E., Ramos, L. A., and Chirat, C.: Studies on fluorescence of cellulosics, Holzforschung, 61, 504-508, doi:10.1515/hf.2007.090, 2007. 
Chance, B., Schoener, B., Oshino, R., Itshak, F., and Nakase, Y.: Oxidation-reduction ratio studies of mitochondria in freezetrapped samples - NADH and flavoprotein fluorescence signals, J. Biol. Chem., 254, 4764-4771, 1979.

Chang, J. L. and Thompson, J. E.: Characterization of colored products formed during irradiation of aqueous solutions containing $\mathrm{H}_{2} \mathrm{O}_{2}$ and phenolic compounds, Atmos. Environ., 44, 541-551, doi:10.1016/j.atmosenv.2009.10.042, 2010.

Chang, S. K., Mirabal, Y. N., Atkinson, E. N., Cox, D., Malpica, A., Follen, M., and Richards-Kortum, R.: Combined reflectance and fluorescence spectroscopy for in vivo detection of cervical pre-cancer, J. Biomed. Opt., 10, 024031, doi:10.1117/1.1899686, 2005.

Chen, J., LeBoef, E. J., Dai, S., and Gu, B. H.: Fluorescence spectroscopic studies of natural organic matter fractions, Chemosphere, 50, 639-647, 2003.

Cheng, Y. S., Barr, E. B., Fan, B. J., Hargis, P. J., Rader, D. J., O'Hern, T. J., Torczynski, J. R., Tisone, G. C., Preppernau, B. L., Young, S. A., and Radloff, R. J.: Detection of bioaerosols using multiwavelength UV fluorescence spectroscopy, Aerosol Sci. Tech., 30, 186-201, 1999.

Chi, M. C. and Li, C. S.: Fluorochrome in monitoring atmospheric bioaerosols and correlations with meteoro ogical factors and air pollutants, Aerosol Sci. Tech., 41, 672-678, doi:10.1080/02786820701383181, 2007.

Christner, B. C., Morris, C. E., Foreman, C. M., Cai, R. M., and Sands, D. C.: Ubiquity of biological ice nucleators in snowfall, Science, 319, 1214-1214, doi:10.1126/science.1149757, 2008.

Coble, P. G.: Characterization of marine and terrestrial DOM in seawater using excitation emission matrix spectroscopy, Mar. Chem., 51, 325-346, 1996.

Coble, P. G., Green, S. A., Blough, N. V., and Gagosian, R. B.: Characterization of dissolved organic-matter in the black-sea by fluorescence spectroscopy, Nature, 348, 432-435, 1990.

Cox, C. S. and Wathes, C. M.: Bioaerosols handbook, Lewis, Boca Raton, 1995.

Creed, D.: The photophysics and photochemistry of the near-UV absorbing amino-acids -2 . Tyrosine and its simple derivaties, Photochem. Photobiol., 39, 563-575, 1984a.

Creed, D.: The photophysics and photochemistry of the near-UV absorbing amino-acids -1 . Tryptophan and its simple derivatives, Photochem. Photobiol., 39, 537-562, 1984b.

DaCosta, R. S., Andersson, H., and Wilson, B. C.: Molecular fluorescence excitation-emission matrices relevant to tissue spectroscopy, Photochem. Photobiol., 78, 384-392, 2003.

Dalterio, R. A., Nelson, W. H., Britt, D., Sperry, J. F., Tanguay, J. F., and Suib, S. L.: The steady-state and decay characteristics of primary fluorescence from live bacteria, Appl. Spectrosc., 41, 234-241, 1987.

Davitt, K., Song, Y. K., Patterson, W. R., Nurmikko, A. V., Gherasimova, M., Han, J., Pan, Y. L., and Chang, R. K.: 290 and 340 nm UV LED arrays for fluorescence detection from single airborne particles, Opt. Express, 13, 9548-9555, 2005.

Després, V. R., Nowoisky, J. F., Klose, M., Conrad, R., Andreae, M. O., and Pöschl, U.: Characterization of primary biogenic aerosol particles in urban, rural, and high-alpine air by DNA sequence and restriction fragment analysis of ribosomal RNA genes, Biogeosciences, 4, 1127-1141, doi:10.5194/bg-4-1127-2007, 2007.
Després, V. R., Huffman, J. A., Burrows, S. M., Hoose, C., Safatov, A. S., Buryak, G. A., Fröhlich-Nowoisky, J., Elbert, W., Andreae, M. O., Pöschl, U., and Jaenicke, R.: Primary Biological Aerosol Particles in the Atmosphere: A Review, Tellus B, in press, 2012.

Dingle, A. N.: Pollens as condensation nuclei, Journal de Recherches Atmospheriques, 2, 231-237, 1966.

Dix, T. A. and Marnett, L. J.: Metabolism of polycyclic aromatic hydrocarbon derivatives to ultimate carcinogens during lipidperoxidation, Science, 221, 77-79, 1983.

Donaldson, L. A.: Lignification and lignin topochemistry - an ultrastructural view, Phytochemistry, 57, 859-873, 2001.

Donaldson, L. A., Singh, A. P., Yoshinaga, A., and Takabe, K.: Lignin distribution in mild compression wood of Pinus radiata, Can. J. Bot.-Rev. Can. Bot., 77, 41-50, 1999.

Douwes, J., Thorne, P., Pearce, N., and Heederik, D.: Bioaerosol health effects and exposure assessment: Progress and prospects, Ann. Occup. Hyg., 47, 187-200, doi:10.1093/annhyg/meg032, 2003.

Dreyer, B., Morte, A., Perez-Gilabert, M., and Honrubia, M.: Autofluorescence detection of arbuscular mycorrhizal fungal structures in palm roots: an underestimated experimental method, Mycol. Res., 110, 887-897, doi:10.1016/j.mycres.2006.05.011, 2006.

Duarte, R., Pio, C. A., and Duarte, A. C.: Synchronous scan and excitation-emission matrix fluorescence spectroscopy of watersoluble organic compounds in atmospheric aerosols, J. Atmos. Chem., 48, 157-171, 2004.

Elbert, W., Taylor, P. E., Andreae, M. O., and Pöschl, U.: Contribution of fungi to primary biogenic aerosols in the atmosphere: wet and dry discharged spores, carbohydrates, and inorganic ions, Atmos. Chem. Phys., 7, 4569-4588, doi:10.5194/acp-7-4569-2007, 2007.

Eldred, G. E., Miller, G. V., Stark, W. S., and Feeneyburns, L.: Lipofuscin - Resolution of discrepant fluorescence data, Science, 216, 757-759, 1982.

Eng, J., Lynch, R. M., and Balaban, R. S.: Nicotinamide adeninedinucleotide fluorescence spectroscopy and imaging of isolated cardaic myocytes, Biophys. J., 55, 621-630, 1989.

Estes, C., Duncan, A., Wade, B., Lloyd, C., Ellis, W., and Powers, L.: Reagentless detection of microorganisms by intrinsic fluorescence, Biosens. Bioelectron., 18, 511-519, doi:10.1016/s09565663(03)00008-3, 2003.

Ewald, M., Belin, C., Berger, P., and Weber, J. H.: Corrected fluorescence-spectra of fulvic-acids isolated from soil and water, Environ. Sci. Technol., 17, 501-504, 1983.

Farabegoli, G., Hellinga, C., Heijnen, J. J., and van Loosdrecht, M. C. M.: Study on the use of NADH fluorescence measurements for monitoring wastewater treatment systems, Water Res., 37, 2732-2738, doi:10.1016/s0043-1354(03)00064-2, 2003.

Fergenson, D. P., Pitesky, M. E., Tobias, H. J., Steele, P. T., Czerwieniec, G. A., Russell, S. C., Lebrilla, C. B., Horn, J. M., Coffee, K. R., Srivastava, A., Pillai, S. P., Shih, M. T. P., Hall, H. L., Ramponi, A. J., Chang, J. T., Langlois, R. G., Estacio, P. L., Hadley, R. T., Frank, M., and Gard, E. E.: Reagentless detection and classification of individual bioaerosol particles in seconds, Anal. Chem., 76, 373-378, doi:10.1021/ac034467e, 2004. 
Feugnet, G., Lallier, E., Grisard, A., McIntosh, L., Hellstrom, J. E., Jelger, P., Laurell, F., Albano, C., Kaliszewski, M., Wlodarski, M., Mlynczak, J., Kwasny, M., Zawadzki, Z., Mierczyk, Z., Kopczynski, K., Rostedt, A., Putkiranta, M., Marjamaki, M., Keskinen, J., Enroth, J., Janka, K., Reinivaara, R., Holma, L., Humppi, T., Battistelli, E., Iliakis, E., and Gerolimos, G.: Improved laser-induced fluorescence method for bio-attack early warning detection system, Proc. SPIE - Int. Soc. Opt. Eng., 7116, 71160C, doi:10.1117/12.799151, 2008 .

Finlayson-Pitts, B. J. and Pitts, J. N.: Chemistry of the upper and lower atmosphere, Academic press, San Diego, USA, 2000.

Foot, V. E., Kaye, P. H., Stanley, W. R., Barrington, S. J., Gallagher, M., and Gabey, A.: Low-cost real-time multi-parameter bioaerosol sensors, Proc. SPIE - Int. Soc. Opt. Eng., 7116, 711601, doi:10.1117/12.800226, 2008.

Franze, T., Weller, M. G., Niessner, R., and Pöschl, U.: Protein nitration by polluted air, Environ. Sci. Technol., 39, 1673-1678, doi:10.1021/es0488737, 2005.

French, C. S., Smith, J. H. C., Virgin, H. I., and Airth, R. L.: Fluorescence-spectrum curves of chlorophylls, pheophytins, phycoerythrins, phycocyanins and hypericin, Plant Physiol., 31, 369-374, 1956.

Fröhlich-Nowoisky, J., Pickersgill, D. A., Després, V. R., and Pöschl, U.: High diversity of fungi in air particulate matter, P. Natl. Acad. Sci. USA, 106, 12814-12819, doi:10.1073/pnas.0811003106, 2009.

Gabey, A. M., Gallagher, M. W., Whitehead, J., Dorsey, J. R., Kaye, P. H., and Stanley, W. R.: Measurements and comparison of primary biological aerosol above and below a tropical forest canopy using a dual channel fluorescence spectrometer, Atmos. Chem. Phys., 10, 4453-4466, doi:10.5194/acp-10-4453-2010, 2010.

Gabey, A. M., Stanley, W. R., Gallagher, M. W., and Kaye, P. H.: The fluorescence properties of aerosol larger than $0.8 \mu \mathrm{m}$ in urban and tropical rainforest locations, Atmos. Chem. Phys., 11, 5491-5504, doi:10.5194/acp-11-5491-2011, 2011.

Gaft, M., Panczer, G., Reisfeld, R., and Uspensky, E.: Laserinduced time-resolved luminescence as a tool for rare-earth element identification in minerals, Phys. Chem. Miner., 28, 347363, 2001

Galland, P. and Senger, H.: The role of flavins as photoreceptors, J. Photochem. Photobiol. B, 1, 277-294, 1988.

Galland, P. and Tolle, N.: Light-induced fluorescence changes in Phycomyces: evidence for blue light-receptor associated flavosemiquinones, Planta, 217, 971-982, doi:10.1007/s00425-0031068-6, 2003.

Galland, P., Keiner, P., Dornemann, D., Senger, H., Brodhun, B., and Hader, D. P.: Pterin-like and flavin-like fluorescence associated with isolated flagella of euglena-gracilis, Photochem. Photobiol., 51, 675-680, 1990.

Georgakopoulos, D. G., Després, V., Fröhlich-Nowoisky, J., Psenner, R., Ariya, P. A., Pósfai, M., Ahern, H. E., Moffett, B. F., and Hill, T. C. J.: Microbiology and atmospheric processes: biological, physical and chemical characterization of aerosol particles, Biogeosciences, 6, 721-737, doi:10.5194/bg-6-721-2009, 2009

Gillette, D. A. and Walker, T. R.: Characteristics of airborne particles produced by wind erosion of sandy soil, high plains of west Texas, Soil Sci., 123, 97-110, 1977.
Glazer, A. N.: Phycobiliproteins - A family of valuable, widely used fluorophores, J. Appl. Phycol., 6, 105-112, 1994.

Gomez, B. L. and Nosanchuk, J. D.: Melanin and fungi, Curr. Opin. Infect. Dis., 16, 91-96, doi:10.1097/01.aco.0000065076.06965.04, 2003.

Graber, E. R. and Rudich, Y.: Atmospheric HULIS: How humiclike are they? A comprehensive and critical review, Atmos. Chem. Phys., 6, 729-753, doi:10.5194/acp-6-729-2006, 2006.

Gregory, P. H.: The Microbiology of the Atmosphere, Wiley, New York, 1973.

Griffiths, W. D. and Decosemo, G. A. L.: The Assessment of Bioaerosols - A Critical Review, J. Aerosol Sci., 25, 1425-1458, 1994.

Hairston, P. P., Ho, J., and Quant, F. R.: Design of an instrument for real-time detection of bioaerosols using simultaneous measurement of particle aerodynamic size and intrinsic fluorescence, J. Aerosol Sci., 28, 471-482, 1997.

Harris, P. J. and Hartley, R. D.: Detection of bound ferulic acid in cell-walls of gramineae by ultraviolet fluorescence microscopy, Nature, 259, 508-510, 1976.

Hawley, R. J. and Eitzen, E. M.: Biological weapons - A primer for microbiologists, Annu. Rev. Microbiol., 55, 235-253, 2001.

He, X. Q., Li, S. W., Hu, Y. X., and Lin, J. X.: Microspectrofluorometric analysis of autofluorescence in the cell walls of Phyllostachys pubescens Culm, Acta Bot. Sin., 41, 711-714, 1999.

Heald, C. L. and Spracklen, D. V.: Atmospheric budget of primary biological aerosol particles from fungal spores, Geophys. Res. Lett., 36, L09806, doi:10.1029/2009gl037493, 2009.

Heidelberg, J. F., Shahamat, M., Levin, M., Rahman, I., Stelma, G., Grim, C., and Colwell, R. R.: Effect of aerosolization on culturability and viability of gram-negative bacteria, Appl. Environ. Microbiol., 63, 3585-3588, 1997.

Heikal, A. A.: Intracellular coenzymes as natural biomarkers for metabolic activities and mitochondrial anomalies, Biomark. Med., 4, 241-263, doi:10.2217/bmm.10.1, 2010.

Hill, S. C., Pinnick, R. G., Nachman, P., Chen, G., Chang, R. K., Mayo, M. W., and Fernandez, G. L.: Aerosol-fluorescence spectrum analyzer - Real-time measurement of emission-spectra of airborne biological particles, Appl. Optics, 34, 7149-7155, 1995.

Hill, S. C., Mayo, M. W., and Chang, R. K.: Fluorescence of bacteria, pollens, and naturally occurring airborne particles: excitation/emission spectra Army report, ARL-TR-4722, 2009.

Hirayama, K., Akashi, S., Furuya, M., and Fukuhara, K.: Rapid confirmation and revision of the primary structure of bovine serum-albumin by ESIMS and FRIT-FAB LC MS, Biochem. Biophys. Res. Commun., 173, 639-646, 1990.

Ho, J.: Future of biological aerosol detection, Anal. Chim. Acta, 457, 125-148, 2002.

Hobbie, J. E., Daley, R. J., and Jasper, S.: Use of nuclepore filters for counting bacteria by fluorescence microcopy, Appl. Environ. Microbiol., 33, 1225-1228, 1977.

Hohl, N., Galland, P., and Senger, H.: Altered pterin patterns in photobehavioral mutants of phycomyces-blakesleeanus, Photochem. Photobiol., 55, 239-245, 1992.

Hoose, C., Kristjansson, J. E., and Burrows, S. M.: How important is biological ice nucleation in clouds on a global scale?, Environ. Res. Lett., 5, 024009, doi:10.1088/1748-9326/5/2/024009, 2010. 
Huang, S. H., Heikal, A. A., and Webb, W. W.: Two-photon fluorescence spectroscopy and microscopy of NAD $(\mathrm{P}) \mathrm{H}$ and flavoprotein, Biophys. J., 82, 2811-2825, 2002.

Hudson, N., Baker, A., and Reynolds, D.: Fluorescence analysis of dissolved organic matter in natural, waste and polluted waters A review, River Res. Appl., 23, 631-649, doi:10.1002/rra.1005, 2007.

Huffman, J. A., Treutlein, B., and Pöschl, U.: Fluorescent biological aerosol particle concentrations and size distributions measured with an Ultraviolet Aerodynamic Particle Sizer (UVAPS) in Central Europe, Atmos. Chem. Phys., 10, 3215-3233, doi:10.5194/acp-10-3215-2010, 2010.

Huffman, J. A., Sinha, B., Garland, R. M., Gunthe, S., Artaxo, P., Martin, S., Andreae, M. O., and Pöschl, U.: Fluorescent biological aerosol particle concentrations and size distributions measured in pristine tropical rainforest air during AMAZE-08, Atmos. Chem. Phys., in preparation, 2012.

Jabajihare, S. H., Perumalla, C. J., and Kendrick, W. B.: Autofluorescence of vesicles, arbuscules, and intercellular hyphae of a versicular-arbuscular fungus in leek (allium-porrum) roots, Can. J. Bot.-Rev. Can. Bot., 62, 2665-2669, 1984.

Jaenicke, R.: Abundance of cellular material and proteins in the atmosphere, Science, 308, 73, doi:10.1126/science.1106335, 2005.

Jaenicke, R., Matthias-Maser, S., and Gruber, S.: Omnipresence of biological material in the atmosphere, Environ. Chem., 4, 217220, doi:10.1071/en07021, 2007.

Jeys, T. H., Herzog, W. D., Hybl, J. D., Czerwinski, R. N., and Sanchez, A.: Advanced trigger development, Linc. Lab. J., 17, 29-62, 2007.

Jimenez, J. L., Canagaratna, M. R., Donahue, N. M., Prevot, A. S. H., Zhang, Q., Kroll, J. H., DeCarlo, P. F., Allan, J. D., Coe, H., Ng, N. L., Aiken, A. C., Docherty, K. S., Ulbrich, I. M., Grieshop, A. P., Robinson, A. L., Duplissy, J., Smith, J. D., Wilson, K. R., Lanz, V. A., Hueglin, C., Sun, Y. L., Tian, J., Laaksonen, A., Raatikainen, T., Rautiainen, J., Vaattovaara, P., Ehn, M., Kulmala, M., Tomlinson, J. M., Collins, D. R., Cubison, M. J., Dunlea, E. J., Huffman, J. A., Onasch, T. B., Alfarra, M. R., Williams, P. I., Bower, K., Kondo, Y., Schneider, J., Drewnick, F., Borrmann, S., Weimer, S., Demerjian, K., Salcedo, D., Cottrell, L., Griffin, R., Takami, A., Miyoshi, T., Hatakeyama, S., Shimono, A., Sun, J. Y., Zhang, Y. M., Dzepina, K., Kimmel, J. R., Sueper, D., Jayne, J. T., Herndon, S. C., Trimborn, A. M., Williams, L. R., Wood, E. C., Middlebrook, A. M., Kolb, C. E., Baltensperger, U., and Worsnop, D. R.: Evolution of Organic Aerosols in the Atmosphere, Science, 326, 1525-1529, doi:10.1126/science.1180353, 2009.

Johansson, L. and Liden, G.: A study of long-term effects on plasmid-containing Escherichia coli in carbon-limited chemostat using 2D-fluorescence spectrofluorimetry, Biotechnol. Prog., 22, 1132-1139, doi:10.1021/bp060061m, 2006.

Jones, A. M. and Harrison, R. M.: The effects of meteorological factors on atmospheric bioaerosol concentrations - a review, Sci. Total Environ., 326, 151-180, doi:10.1016/j.scitotenv.2003.11.021, 2004.

Kamboj, D. V., Goel, A. K., and Singh, L.: Biological warfare agents, Def. Sci. J., 56, 495-506, 2006.
Kayatz, P., Thumann, G., Luther, T. T., Jordan, J. F., Bartz-Schmidt, K. U., Esser, P. J., and Schraermeyer, U.: Oxidation causes melanin fluorescence, Invest. Ophthalmol. Vis. Sci., 42, 241246, 2001.

Kaye, P. H., Barton, J. E., Hirst, E., and Clark, J. M.: Simultaneous light scattering and intrinsic fluorescence measurement for the classification of airborne particles, Appl. Optics, 39, 3738-3745, 2000.

Kaye, P. H., Stanley, W. R., Hirst, E., Foot, E. V., Baxter, K. L., and Barrington, S. J.: Single particle multichannel bio-aerosol fluorescence sensor, Opt. Express, 13, 3583-3593, 2005.

Keller, N. P., Turner, G., and Bennett, J. W.: Fungal secondary metabolism - From biochemistry to genomics, Nat. Rev. Microbiol., 3, 937-947, doi:10.1038/nrmicro1286, 2005.

Kepner, R. L. and Pratt, J. R.: Use of fluorochromes for direct enumeration of total bacteria in environmental-samples - Past and present, Microbiol. Rev., 58, 603-615, 1994.

Kieber, R. J., Whitehead, R. F., Reid, S. N., Willey, J. D., and Seaton, P. J.: Chromophoric dissolved organic matter (CDOM) in rainwater, southeastern North Carolina, USA, J. Atmos. Chem., 54, 21-41, doi:10.1007/s10874-005-9008-4, 2006.

Klapper, L., McKnight, D. M., Fulton, J. R., Blunt-Harris, E. L., Nevin, K. P., Lovley, D. R., and Hatcher, P. G.: Fulvic acid oxidation state detection using fluorescence spectroscopy, Environ. Sci. Technol., 36, 3170-3175, doi:10.1021/es0109702, 2002.

Klapper, M. H.: Independent distribution of amino-acid near neighbor pairs into polypeptides, Biochem. Biophys. Res. Commun., 78, 1018-1024, 1977.

Klingenberg, M. and Bucher, T.: Biological oxidations, Annu. Rev. Biochem., 29, 669-708, 1960.

Koenig, K. and Schneckenburger, H.: Laser-induced autofluorescence for medical diagnosis, J. Fluoresc., 4, 17-40, doi:10.1007/bf01876650, 1994.

Kopczynski, K., Kwasny, M., Mierczyk, Z., and Zawadzki, Z.: Laser induced fluorescence system for detection of biological agents: European project FABIOLA, Proc. SPIE - The International Society for Optical Engineering, 5954, 0501-0512, doi:10.1117/12.623013, 2005.

Krivacsy, Z., Gelencser, A., Kiss, G., Meszaros, E., Molnar, A., Hoffer, A., Meszaros, T., Sarvari, Z., Temesi, D., Varga, B., Baltensperger, U., Nyeki, S., and Weingartner, E.: Study on the chemical character of water soluble organic compounds in fine atmospheric aerosol at the Jungfraujoch, J. Atmos. Chem., 39, 235-259, 2001.

Kumke, M. U., Löhmannsröben, H. G., and Roch, T.: Fluorescence spectroscopy of polynuclear aromatic compounds in environmental monitoring, J. Fluoresc., 5, 139-152, doi:10.1007/bf00727531, 1995.

Kunit, M. and Puxbaum, H.: Enzymatic determination of the cellulose content of atmospheric aerosols, Atmos. Environ., 30, 12331236, 1996.

Kunnil, J.: Identification Studies of Bacillus Spores Using Fluorescence Spectroscopy, Doctor of Philosophy, Physics and Astronomy, University of Canterbury, New Zealand, Christchurch, 192 pp., 2005.

Lacey, J. and Dutkiewicz, J.: Bioaerosols and occupational lungdisease, J. Aerosol Sci., 25, 1371-1404, 1994. 
Ladokhin, A. S.: Fluorescence spectroscopy in peptide and protein analysis, in: Encyclopedia of analytical chemistry, edited by: Meyers, R. A., John Wiley \& Sons, New York, 5762-5779, 2000.

Lakowicz, J. R.: Principles of Fluorescence Spectroscopy, Plenum publishers, New York, 1999.

Lau, A. P. S., Lee, A. K. Y., Chan, C. K., and Fang, M.: Ergosterol as a biomarker for the quantification of the fungal biomass in atmospheric aerosols, Atmos. Environ., 40, 249-259, doi:10.1016/j.atmosenv.2005.09.048, 2006.

Leblanc, L. and Dufour, E.: Monitoring the identity of bacteria using their intrinsic fluorescence, FEMS Microbiol. Lett., 211, 147-153, 2002.

Lenardon, M. D., Munro, C. A., and Gow, N. A. R.: Chitin synthesis and fungal pathogenesis, Curr. Opin. Microbiol., 13, 416-423, doi:10.1016/j.mib.2010.05.002, 2010.

Lewitzka, F. and Niessner, R.: Application of time-resolved fluorescence spectroscopy on the analysis of PAH-coated aerosols, Aerosol Sci. Tech., 23, 454-464, 1995.

Li, B. and Lin, S. X.: Fluorescence-energy transfer in human estradiol 17 beta-dehydrogenase-NADPH complex and studies on the coenzyme binding, Eur. J. Biochem., 235, 180-186, 1996.

Li, J. K., Asali, E. C., and Humphrey, A. E.: Monitoring cell concentration and activity by multiple excitation fluorometry, Biotechnol. Prog., 7, 21-27, 1991.

Li, W. H., Sheng, G. P., Lu, R., Yu, H. Q., Li, Y. Y., and Harada, H.: Fluorescence spectral characteristics of the supernatants from an anaerobic hydrogen-producing bioreactor, Appl. Microbiol. Biotechnol., 89, 217-224, doi:10.1007/s00253-010-2867-x, 2011.

Li, Y., Dick, W. A., and Tuovinen, O. H.: Fluorescence microscopy for visualization of soil microorganisms - a review, Biol. Fert. Soils, 39, 301-311, doi:10.1007/s00374-004-0722-x, 2004.

Liang, J., Wu, W. L., Liu, Z. H., Mei, Y. J., Cai, R. X., and Shen, P.: Study the oxidative injury of yeast cells by NADH autofluorescence, Spectroc. Acta Pt. A, 67, 355-359, doi:10.1016/j.saa.2006.07.035, 2007.

Lichtenthaler, H. K., Buschmann, C., Rinderle, U., and Schmuck, G.: Application of chlorophyll fluorescence in ecophysiology, Radiat. Environ. Biophys., 25, 297-308, 1986.

Lighthart, B. and Shaffer, B. T.: Airborne bacteria in the atmospheric surface-layer - Temporal distribution above a grass seed field, Appl. Environ. Microbiol., 61, 1492-1496, 1995.

Lim, D. V., Simpson, J. M., Kearns, E. A., and Kramer, M. F.: Current and developing technologies for monitoring agents of bioterrorism and biowarfare, Clin. Microbiol. Rev., 18, 583-607, doi:10.1128/cmr.18.4.583-607.2005, 2005.

Linskens, H. F. and Cresti, M.: Pollen-allergy as an ecological phenomenon: a review, Plant Biosyst., 134, 341-352, 2000.

Lohmann, U. and Feichter, J.: Global indirect aerosol effects: a review, Atmos. Chem. Phys., 5, 715-737, doi:10.5194/acp-5-7152005, 2005.

Madelin, T. M.: Fungal aerosols: A review, J. Aerosol Sci., 25, 1405-1412, 1994.

Manninen, A., Putkiranta, M., Rostedt, A., Saarela, J., Laurila, T., Marjamaki, M., Keskinen, J., and Hernberg, R.: Instrumentation for measuring fluorescence cross sections from airborne microsized particles, Appl. Optics, 47, 110-115, 2008.
Mantoura, R. F. C. and Llewellyn, C. A.: The rapiddetermination of algal chlorophyll and carotenoid-pigments and their breakdown products in natural-waters by reverse-phase high-performance liquid-chromatography, Anal. Chim. Acta, 151, 297-314, 1983.

Marose, S., Lindemann, C., and Scheper, T.: Two-dimensional fluorescence spectroscopy: A new tool for on-line bioprocess monitoring, Biotechnol. Prog., 14, 63-74, 1998.

Martell, A. E.: Vitamin-B6 catalyzed-reactions of alpha-amino and alpha-keto acids - Model systems, Accounts Chem. Res., 22, 115-124, 1989.

Matthias-Maser, S., Obolkin, V., Khodzer, T., and Jaenicke, R.: Seasonal variation of primary biological aerosol particles in the remote continental region of Lake Baikal/Siberia, Atmos. Environ., 34, 3805-3811, doi:10.1016/s1352-2310(00)00139-4, 2000.

McFeters, G. A., Yu, F. P. P., Pyle, B. H., and Stewart, P. S.: Physiological assessment of bacteria using fluorochromes, J. Microbiol Meth., 21, 1-13, 1995.

McIntosh, A., Atshaves, B., Huang, H., Gallegos, A., Kier, A., and Schroeder, F.: Fluorescence Techniques Using Dehydroergosterol to Study Cholesterol Trafficking, Lipids, 43, 1185-1208, doi:10.1007/s11745-008-3194-1, 2008.

Miano, T. M., Sposito, G., and Martin, J. P.: Fluorescence spectroscopy of humic substances, Soil Sci. Soc. Am. J., 52, 10161019, 1988.

Miao, H., Rubakhin, S. S., and Sweedler, J. V.: Analysis of serotonin release from single neuron soma using capillary electrophoresis and laser-induced fluorescence with a pulsed deep-UV NeCu laser, Anal. Bioanal. Chem., 377, 1007-1013, doi:10.1007/s00216-003-2191-8, 2003.

Michal, G.: Biochemical pathways, Spectrum Akademischer Verlag, Berlin, 1999.

Moberg, L., Robertsson, G., and Karlberg, B.: Spectrofluorimetric determination of chlorophylls and pheopigments using parallel factor analysis, Talanta, 54, 161-170, 2001.

Möhler, O., DeMott, P. J., Vali, G., and Levin, Z.: Microbiology and atmospheric processes: the role of biological particles in cloud physics, Biogeosciences, 4, 1059-1071, doi:10.5194/bg-4-10592007, 2007.

Monks, P. S., Granier, C., Fuzzi, S., Stohl, A., Williams, M. L., Akimoto, H., Amann, M., Baklanov, A., Baltensperger, U., Bey, I., Blake, N., Blake, R. S., Carslaw, K., Cooper, O. R., Dentener, F., Fowler, D., Fragkou, E., Frost, G. J., Generoso, S., Ginoux, P., Grewe, V., Guenther, A., Hansson, H. C., Henne, S., Hjorth, J., Hofzumahaus, A., Huntrieser, H., Isaksen, I. S. A., Jenkin, M. E., Kaiser, J., Kanakidou, M., Klimont, Z., Kulmala, M., Laj, P., Lawrence, M. G., Lee, J. D., Liousse, C., Maione, M., McFiggans, G., Metzger, A., Mieville, A., Moussiopoulos, N., Orlando, J. J., O'Dowd, C. D., Palmer, P. I., Parrish, D. D., Petzold, A., Platt, U., Pöschl, U., Prevot, A. S. H., Reeves, C. E., Reimann, S., Rudich, Y., Sellegri, K., Steinbrecher, R., Simpson, D., ten Brink, H., Theloke, J., van der Werf, G. R., Vautard, R., Vestreng, V., Vlachokostas, C., and von Glasow, R.: Atmospheric composition change - global and regional air quality, Atmos. Environ., 43, 5268-5350, doi:10.1016/j.atmosenv.2009.08.021, 2009.

Muller, C. L., Baker, A., Hutchinson, R., Fairchild, I. J., and Kidd, C.: Analysis of rainwater dissolved organic carbon compounds using fluorescence spectrophotometry, Atmos. Environ., 
42, 8036=-8045, doi:10.1016/j.atmosenv.2008.06.042, 2008.

Nielsen, T., Seitz, B., and Ramdahl, T.: Occurrence of nitro-PAH in the atmosphere in a rural area, Atmos. Environ., 18, 2159-2165, 1984.

Niessner, R. and Krupp, A.: Detection and chemical characterization of polycyclic aromatic hydrocarbon aerosols by means of laser-induced fluorescence, Part. Part. Syst. Charact., 8, 23-28, 1991.

Niklas, K. J.: The cell walls that bind the tree of life, Bioscience, 54, 831-841, 2004.

Nisbet, A. D., Saundry, R. H., Moir, A. J. G., Fothergill, L. A., and Fothergill, J. E.: The complete amino-acid-sequence of hen ovalbumin, Eur. J. Biochem., 115, 335-345, 1981.

Nosanchuk, J. D. and Casadevall, A.: The contribution of melanin to microbial pathogenesis, Cell Microbiol., 5, 203-223, 2003.

O’Connor, D. J., Iacopino, D., Healy, D. A., O’Sullivan, D., and Sodeau, J. R.: The intrinsic fluorescence spectra of selected pollen and fungal spores, Atmos. Environ., 45, 6451-6458, doi:10.1016/j.atmosenv.2011.07.044, 2011.

Olmstead, J. A. and Gray, D. G.: Fluorescence emission from mechanical pulp sheets, J. Photochem. Photobiol. A, 73, 59-65, 1993.

Olmstead, J. A. and Gray, D. G.: Fluorescence spectroscopy of cellulose, lignin and mechanical pulps: A review, J. Pulp Pap. Sci., 23, J571-J581, 1997.

Paidhungat, M., Setlow, B., Driks, A., and Setlow, P.: Characterization of spores of Bacillus subtilis which lack dipicolinic acid, J. Bacteriol., 182, 5505-5512, 2000.

Pan, Y. L., Pinnick, R. G., Hill, S. C., and Chang, R. K.: Particle-Fluorescence Spectrometer for Real-Time SingleParticle Measurements of Atmospheric Organic Carbon and Biological Aerosol, Environ. Sci. Technol., 43, 429-434, doi:10.1021/es801544y, 2009.

Pan, Y.-L., Hill, S. C., Pinnick, R. G., Huang, H., Bottiger, J. R., and Chang, R. K.: Fluorescence spectra of atmospheric aerosol particles measured using one or two excitation wavelengths: Comparison of classification schemes employing different emission and scattering results, Opt. Express, 18, 1243612457, doi:10.1364/oe.18.012436, 2010.

Pan, Y.-L., Hill, S. C., Pinnick, R. G., House, J. M., Flagan, R. C., and Chang, R. K.: Dual-excitation-wavelength fluorescence spectra and elastic scattering for differentiation of single airborne pollen and fungal particles, Atmos. Environ., 45, 1555-1563, doi:10.1016/j.atmosenv.2010.12.042, 2011.

Panne, U., Knoller, A., Kotzick, R., and Niessner, R.: On-line and in-situ detection of polycyclic aromatic hydrocarbons (PAH) on aerosols via thermodesorption and laser-induced fluorescence spectroscopy, Fresen. J. Anal. Chem., 366, 408-414, 2000.

Parker, E. P., Trahan, M. W., Wagner, J. S., Rosenthal, S. E., Whitten, W. B., Gieray, R. A., Reilly, P. T. A., Lazar, A. C., and Ramsey, J. M.: Detection and classification of individual airborne microparticles using laser ablation mass spectroscopy and multivariate analysis, Field Anal. Chem. Technol., 4, 31-42, 2000.

Penner, J. E.: Carbonaceous aerosols influencing atmospheric radiation: Black and organic carbon, Medium: P; Size: 35 p., 1994.

Permyakov, E. A.: Luminescent spectroscopy of proteins, CRC Press, Boca Raton, 1993.
Petit, P. X., Gendron, M. C., Schrantz, N., Metivier, D., Kroemer, G., Maciorowska, Z., Sureau, F., and Koester, S.: Oxidation of pyridine nucleotides during Fas- and ceramide-induced apoptosis in Jurkat cells: correlation with changes in mitochondria, glutathione depletion, intracellular acidification and caspase 3 activation, Biochem. J., 353, 357-367, 2001.

Pinnick, R. G., Hill, S. C., Nachman, P., Pendleton, J. D., Fernandez, G. L., Mayo, M. W., and Bruno, J. G.: Fluorescence Particle Counter for Detecting Airborne Bacteria and Other Biological Particles, Aerosol Sci. Tech., 23, 653-664, 1995.

Pinnick, R. G., Hill, S. C., Pan, Y. L., and Chang, R. K.: Fluorescence spectra of atmospheric aerosol at Adelphi, Maryland, USA: measurement and classification of single particles containing organic carbon, Atmos. Environ., 38, 1657-1672, doi:10.1016/j.atmosenv.2003.11.017, 2004.

Pöhlker, C., Huffman, J. A., and Pöschl, U.: Autofluorescence of Bioaerosol Standards, in preparation, 2012.

Pöschl, U.: Atmospheric aerosols: Composition, transformation, climate and health effects, Angew. Chem.-Int. Edit., 44, 7520 7540, doi:10.1002/anie.200501122, 2005.

Pöschl, U., Martin, S. T., Sinha, B., Chen, Q., Gunthe, S. S., Huffman, J. A., Borrmann, S., Farmer, D. K., Garland, R. M., Helas, G., Jimeney, J. L., King, S. M., Manzi, A., Mikhailov, E., Pauliquevis, T., Petters, M. D., Prenni, A. J., Roldin, P., Rose, D., Schneider, J., Su, H., Zorn, S. R., Artaxo, P., and Andreae, M. O.: Rainforest Aerosols as Biogenic Nuclei of Clouds and Precipitation in the Amazon, Science, 329, 15131516, doi:10.1126/science.1191056, 2010.

Pons, M. N., Le Bonte, S., and Potier, O.: Spectral analysis and fingerprinting for biomedia characterisation, J. Biotechnol., 113, 211-230, doi:10.1016/j.jbiotec.2004.03.028, 2004.

Primmerman, C. A.: Detection of biological agents, Linc. Lab. J., 12, 3-32, 2000.

Ramanujam, N.: Fluorescence spectroscopy of neoplastic and nonneoplastic tissues, Neoplasia, 2, 89-117, 2000.

Ramanujam, N.: Fluorescence Spectroscopy In Vivo, Encyclopedia of Analytical Chemistry, John Wiley \& Sons, Ltd, 2006.

Reisfeld, R., Gaft, M., Boulon, G., Panczer, C., and Jorgensen, C. K.: Laser-induced luminescence of rare-earth elements in natural fluor-apatites, J. Lumines., 69, 343-353, 1996.

Rembold, H. and Gyure, W. L.: Biochemistry of pteridines, Angew. Chem.-Int. Edit. Engl., 11, 1061-1072, 1972.

RichardsKortum, R. and Sevick Muraca, E.: Quantitative optical spectroscopy for tissue diagnosis, Annu. Rev. Phys. Chem., 47, 555-606, 1996.

Roberts, M. F. W.: Alkaloids: Biochemistry, Ecology, and Medicinal Applications, Plenum Press, New York, 1998.

Rosenheim, O.: Note on the induced fluorescence of ergosterol, Biochem. J., 21, 1335, 1927.

Roshchina, V. V.: Autofluorescence of plant secreting cells as a biosensor and bioindicator reaction, J. Fluoresc., 13, 403-420, 2003.

Roshchina, V. V.: Allelochemicals as fluorescent markers, dyes and probes, Allelopathy J., 16, 31-46, 2005.

Roshchina, V. V.: Fluorescing world of plant secreting cells, Science Publishers, 2008.

Roshchina, V. V. and Karnaukhov, V. N.: Changes in pollen autofluorescence induced by ozone, Biologia Plantarum, 42, 273-278, 1999. 
Roshchina, V. V. and Mel'nikova, E. V.: Pollen chemosensitivity to ozone and peroxides, Russ. J. Plant Physiol., 48, 74-83, 2001.

Roshchina, V. V., Melnikova, E. V., and Kovaleva, L. V.: Changes in fluorescence during development of the male gametophyte, Russ. J. Plant Physiol., 44, 36-44, 1997.

Roshchina, V. V., Yashin, V. A., and Kononov, A. V.: Autofluorescence of developing plant vegetative microspores studied by confocal microscopy and microspectrofluorimetry, J. Fluoresc., 14, 745-750, 2004.

Roszak, D. B. and Colwell, R. R.: Survival strategies of bacteria in the natural-environment, Microbiol. Rev., 51, 365-379, 1987.

Russell, L. M., Maria, S. F., and Myneni, S. C. B.: Mapping organic coatings on atmospheric particles, Geophys. Res. Lett., 29, 1779, doi:10.1029/2002g1014874, 2002.

Sarasanandarajah, S., Kunnil, J., Bronk, B. V., and Reinisch, L.: Two-dimensional multiwavelength fluorescence spectra of dipicolinic acid and calcium dipicolinate, Appl. Optics, 44, 11821187, 2005.

Schnell, R. C. and Vali, G.: Atmospheric Ice Nuclei from Decomposing Vegetation, Nature, 236, 163-165, 1972.

Seaver, M., Eversole, J. D., Hardgrove, J. J., Cary, W. K., and Roselle, D. C.: Size and fluorescence measurements for field detection of biological aerosols, Aerosol Sci. Tech., 30, 174-185, 1999.

Setlow, B. and Setlow, P.: Levels of oxidized and reduced pyridine nucleotides in dormant spores and during growth, sporulation, and spores germination of bacillus megaterium, J. Bacteriol., 129, 857-865, 1977.

Siano, S. A. and Mutharasan, R.: NADH and flavin fluorescence responses of starved yeast cultures to substrate additions, Biotechnol. Bioeng., 34, 660-670, 1989.

Sierra, M. M. D., Donard, O. F. X., Lamotte, M., Belin, C., and Ewald, M.: Fluorescence spectroscopy of coastal and marine waters, Mar. Chem., 47, 127-144, 1994.

Sinski, J. F. and Exner, J.: Concentration dependence in the spectra of polycyclic aromatic hydrocarbon mixtures by front-surface fluorescence analysis, Appl. Spectrosc., 61, 970-977, 2007.

Sivaprakasam, V., Huston, A. L., Scotto, C., and Eversole, J. D.: Multiple UV wavelength excitation and fluorescence of bioaerosols, Opt. Express, 12, 4457-4466, 2004.

Sivaprakasam, V., Pletcher, T., Tucker, J. E., Huston, A. L., McGinn, J., Keller, D., and Eversole, J. D.: Classification and selective collection of individual aerosol particles using laserinduced fluorescence, Appl. Optics, 48, B126-B136, 2009.

Slieman, T. A. and Nicholson, W. L.: Role of dipicolinic acid in survival of Bacillus subtilis spores exposed to artificial and solar UV radiation, Appl. Environ. Microbiol., 67, 1274-1279, 2001.

Slowik, J. G., Cross, E. S., Han, J. H., Kolucki, J., Davidovits, P., Williams, L. R., Onasch, T. B., Jayne, J. T., Kolb, C. E., and Worsnop, D. R.: Measurements of morphology changes of fractal soot particles using coating and denuding experiments: Implications for optical absorption and atmospheric lifetime, Aerosol Sci. Tech., 41, 734-750, doi:10.1080/02786820701432632, 2007.

Snyder, A. P., Maswadeh, W. M., Tripathi, A., Eversole, J., Ho, J., and Spence, M.: Orthogonal analysis of mass and spectral based technologies for the field detection of bioaerosols, Anal. Chim. Acta, 513, 365-377, doi:10.1016/j.aca.2004.03.003, 2004.
Spurny, K. R.: On the chemical-detection of bioaerosols, J. Aerosol Sci., 25, 1533-1547, 1994.

Stanley, W. R., Kaye, P. H., Foot, V. E., Barrington, S. J., Gallagher, M., and Gabey, A.: Continuous bioaerosol monitoring in a tropical environment using a UV fluorescence particle spectrometer, Atmos. Sci. Lett., 12, 195-199, doi:10.1002/as1.310, 2011.

Stewart, A. J. and Wetzel, R. G.: Fluorescence - absorbance ratios - a molecular-weight tracer of dissolved organic-matter, Limnol. Oceanogr., 25, 559-564, 1980.

Sun, J. M. and Ariya, P. A.: Atmospheric organic and bio-aerosols as cloud condensation nuclei (CCN): A review, Atmos. Environ., 40, 795-820, doi:10.1016/j.atmosenv.2005.05.052, 2006.

Taiz, L. and Zeiger, E.: Plant Physiology, Sinauer Associates, Incorporated, 2010.

Teale, F. W. J. and Weber, G.: Ultraviolet fluorescence of the aromatic amino acids, Biochem. J., 65, 476-482, 1957.

Theis, N. and Lerdau, M.: The evolution of function in plant secondary metabolites, Int. J. Plant Sci., 164, S93-S102, 2003.

Thygesen, L. G., Rinnan, A., Barsberg, S., and Moller, J. K. S.: Stabilizing the PARAFAC decomposition of fluorescence spectra by insertion of zeros outside the data area, Chemometr. Intell. Lab. Syst., 71, 97-106, doi:10.1016/j.chemolab.2003.12.012, 2004.

Tsuchida, M., Miura, T., and Aibara, K.: Lipofuscin and lipofuscinlike substances, Chem. Phys. Lipids, 44, 297-325, 1987.

Tyagi, A. and Penzkofer, A.: Fluorescence spectroscopic behaviour of folic acid, Chem. Phys., 367, 83-92, doi:10.1016/j.chemphys.2009.10.026, 2010.

Uchiyama, S., Nagai, S., and Maruyama, K.: Lumazine-like fluorescence in a mass of spores of the cellular slime mold, Dictyostelium discoideum, J. Plant Res., 110, 383-386, 1997.

van Wuijckhuijse, A. L., Stowers, M. A., Kleefsman, W. A., van Baar, B. L. M., Kientz, C. E., and Marijnissen, J. C. M.: Matrixassisted laser desorption/ionisation aerosol time-of-flight mass spectrometry for the analysis of bioaerosols: development of a fast detector for airborne biological pathogens, J. Aerosol Sci., 36, 677-687, doi:10.1016/j.jaerosci.2004.11.003, 2005.

Vierheilig, H., Bockenhoff, A., Knoblauch, M., Juge, C., Van Bel, A. J. E., Grundler, F., Piche, Y., and Wyss, U.: In vivo observations of the arbuscular mycorrhizal fungus Glomus mosseae in roots by confocal laser scanning microscopy, Mycol. Res., 103, 311-314, 1999.

Vining, L. C.: Functions of secondary metabolites, Annu. Rev. Microbiol., 44, 395-427, 1990.

Vishwasrao, H. D., Heikal, A. A., Kasischke, K. A., and Webb, W. W.: Conformational dependence of intracellular NADH on metabolic state revealed by associated fluorescence anisotropy, J. Biol. Chem., 280, 25119-25126, doi:10.1074/jbc.M502475200, 2005.

Voet, D. and Voet, J. G.: Biochemistry, Bd. 1, J. Wiley \& Sons, 2004.

Wedborg, M., Persson, T., and Larsson, T.: On the distribution of UV-blue fluorescent organic matter in the Southern Ocean, DeepSea Res. Pt. I, 54, 1957-1971, doi:10.1016/j.dsr.2007.07.003, 2007.

Welschmeyer, N. A.: Fluorometric analysis of chlorophyll a in the presence of chlorophyll $\mathrm{b}$ and pheopigments, Limnol. Oceanogr., 39, 1985-1992, 1994.

Wiermann, R. and Vieth, K.: Outer pollen wall, an important accumulation site for flavonoids, Protoplasma, 118, 230-233, 1983. 
Winiwarter, W., Bauer, H., Caseiro, A., and Puxbaum, H.: Quantifying emissions of primary biological aerosol particle mass in Europe, Atmos. Environ., 43, 1403-1409, doi:10.1016/j.atmosenv.2008.01.037, 2009.

Wlodarski, M., Kaliszewski, M., Kwasny, M., Kopczynski, K., Zawadzki, Z., Mierczyk, Z., Mlynczak, J., Trafny, E., and Szpakowska, M.: Fluorescence excitation-emission matrices of selected biological materials, in: Optically Based Biological and Chemical Detection for Defence III, edited by: Carrano, J. C. and Zukauskas, A., Proceedings of the Society of Photo-Optical Instrumentation Engineers - Spie, Spie-Int Soc Optical Engineering, Bellingham, U18-U29, 2006.

Wos, M. and Pollard, P.: Sensitive and meaningful measures of bacterial metabolic activity using NADH fluorescence, Water Res., 40, 2084-2092, doi:10.1016/j.watres.2006.03.020, 2006.

$\mathrm{Xu}, \mathrm{Z} ., \mathrm{Wu}, \mathrm{Y} ., \mathrm{S}$ Shen, F., Chen, Q., Tan, M., and Yao, M.: Bioaerosol Science, Technology, and Engineering: Past, Present, and Future, Aerosol Sci. Tech., 45, 1337-1349, doi:10.1080/02786826.2011.593591, 2011.
Yin, D. Z.: Biochemical basis of lipofuscin, ceroid, and age pigment-like fluorophores, Free Radic. Biol. Med., 21, 871-888, 1996.

Zepp, R. G., Sheldon, W. M., and Moran, M. A.: Dissolved organic fluorophores in southeastern US coastal waters: correction method for eliminating Rayleigh and Raman scattering peaks in excitation-emission matrices, Mar. Chem., 89, 15-36, doi:10.1016/j.marchem.2004.02.006, 2004.

Zipfel, W. R., Williams, R. M., Christie, R., Nikitin, A. Y., Hyman, B. T., and Webb, W. W.: Live tissue intrinsic emission microscopy using multiphoton-excited native fluorescence and second harmonic generation, P. Natl. Acad. Sci. USA, 100, 70757080, doi:10.1073/pnas.0832308100, 2003. 